\title{
Los requisitos de solvencia técnica-profesional. La experiencia ${ }^{1}$
}

\section{The technical-professional solvency requirements. The experience}

\author{
Asunción Nicolás Lucas \\ Universidad de Oviedo (España) \\ ORCID: https://orcid.org/0000-0001-5039-3488 \\ anicolas@uniovi.es
}

\begin{abstract}
NOTA BIOGRÁFICA
Licenciada en Derecho por la Universidad de Oviedo (1989). Doctora en Derecho por la Universidad de Oviedo (1996). Profesora titular de Universidad (desde 1999). Sus líneas de investigación se centran en los contratos administrativos, sanciones administrativas, responsabilidad patrimonial y empleo público. Actualmente trabaja en el ámbito de la protección de datos. Miembro de varios proyectos de investigación tanto a nivel nacional como regional.
\end{abstract}

\section{RESUMEN}

La entrada en vigor de la nueva Ley de Contratos del Sector Público de 2017 ha introducido alguna modificación en el ordenamiento jurídico español, en materia de contratación pública, por exigencias del Derecho comunitario, en aspectos relativos, por ejemplo, a la experiencia exigida a los licitadores como requisito para participar en los procedimientos de licitación. Aspectos que no pueden olvidar que la normativa comunitaria en materia de contratación pública se ha centrado fundamentalmente en las fases de preparación y adjudicación de los contratos públicos con el fin de garantizar los principios de transparencia en los procedimientos de adjudicación, la igualdad entre los licitadores y la apertura a la competencia de los procedimientos de adjudicación, sobre todo cuando los contratos superan determinados umbrales económicos.

Una de las anheladas consecuencias de estas últimas modificaciones se centra en la concreción de la competencia, permitiendo que PYMES y empresas de nueva creación accedan con más facilidad a los procedimientos de licitación, rebajando los plazos necesarios para acreditar la experiencia previa, o permitiendo integrar su propia solvencia a través de medios externos a las mismas.

Un supuesto especial se plantea, como veremos, en relación con los contratos de prestación de servicios jurídicos, enmarcado en un contexto jurídico que difiere en su regulación respecto a la establecida a nivel comunitario y que plantea problemas específicos para acreditar la solvencia y la experiencia de los posibles prestadores de estos servicios.

\section{PALABRAS CLAVE}

Contratos; solvencia; experiencia; selección; servicios jurídicos.

\section{ABSTRACT}

The entry into force of the new Law on Public Sector Contracts of 2017 has introduced some modifications in the Spanish legal system, in terms of public procurement, by requirements of Community law, in some

\footnotetext{
1 Este trabajo se realiza en el Grupo de Investigación "Derecho Administrativo (DA)”, de la Universidad de Oviedo y en el marco del Proyecto de investigación FC-GRUPIN-IDI/2018/000202 de la Consejería de Empleo, Industria y Turismo del Principado de Asturias.
} 
aspects related, for example, to the experience demanded of the bidders as a requirement to participate in tendering procedures. That aspects cannot forget that Community legislation on public procurement has focused mainly on the stages of preparation and awarding of public contracts to guarantee the principles of transparency in award procedures, equality between tenderers and the opening of award procedures to competition, especially when the contracts exceed certain economic thresholds.

One of the desired consequences of these latest changes is focused on the specification of competition, allowing SMEs and start-up companies to access tender procedures more easily, reducing the time required to accredit previous experience, or allowing the integration of their own solvency through external means.

A special assumption arises, as we shall see, in relation to contracts for the provision of legal services, framed in a legal context that differs in its regulation from what is established at Community level and that also raises specific problems to accredit the solvency and experience of the possible providers of these services.

\section{KEYWORDS}

Contrats; solvency; experience; selection; legal services.

\section{SUMARIO}

INTRODUCCIÓN. 1. LA SOLVENCIA TÉCNICA Y PROFESIONAL. EL REQUISITO DE LA EXPERIENCIA. 2. LOS REQUISITOS DE SOLVENCIA COMO CRITERIOS DE SELECCIÓN. 3. LA INTEGRACIÓN DE LA SOLVENCIA CON MEDIOS EXTERNOS. 4. LOS MEDIOS PARA ACREDITAR LA SOLVENCIA TÉCNICA. 5. FORMA DE ACREDITAR LA SOLVENCIA. 6. UN SUPUESTO ESPECIAL: LA CONTRATACIÓN DE SERVICIOS JURÍDICOS. CONCLUSIONES FINALES. BIBLIOGRAFÍA.

\section{INTRODUCCIÓN}

Todavía es relativamente reciente la entrada en vigor de la nueva Ley de Contratos del Sector Público, la Ley 9/1917, de 8 de noviembre, de Contratos del Sector Público, por la que se transponen al ordenamiento jurídico español las Directivas del Parlamento Europeo y del Consejo 2014/23/UE y 2014/24/UE, de 26 de febrero de 2014 (en adelante LCSP). Sin embargo, son muchas ya las líneas que se han escrito sobre los cambios introducidos por la misma, sus pros y sus contras, sus aciertos y sus errores. En las páginas que siguen intentaremos desentrañar algunos de los problemas que afectan a uno de los muchos temas que se regulan en una Ley tan extensa, cual es el de la solvencia técnica, profesional, de los licitadores, precisamente en la fase de licitación del procedimiento de contratación y, más concretamente, el aspecto relativo a la experiencia exigida a los licitadores, que ha sufrido algún que otro cambio con esta última regulación normativa. Analizaremos para ello, aparte de la doctrina en la materia, tanto la jurisprudencia del TJUE como de nuestros propios tribunales, Resoluciones de los Tribunales Administrativos de Recursos Contractuales, Informes de las Juntas Consultivas de Contratación, así como los pliegos de contratación que nos pueden interesar en este estudio.

De acuerdo con el art. 65 LCSP, podrán contratar con las Entidades que conforman el sector público quienes reúnan las siguientes condiciones de aptitud, condiciones sine qua non, cuyo incumplimiento permite la exclusión del licitador que no cumple del procedimiento de adjudicación: la personalidad jurídica y la capacidad jurídica, que se deducen de su propio carácter de persona, tanto física como jurídica, españolas o extranjeras; la capacidad de obrar plena; la habilitación empresarial o profesional; la solvencia económica, financiera y la solvencia técnica o profesional², así como la clasificación cuando lo exija la ley (regulada en

2 La doctrina general en materia de solvencia, respecto a los requisitos exigidos, se resume en la Resolución del TACRC 288/2015, de 29-03-2015, exigencias que se configuran como un requisito o condición sine qua non, cuyo incumplimiento justifica la exclusión de la licitación. También se pueden consultar, entre otros, el informe de la JCCA del Estado 53/10, de 10 de diciembre, o de la JCCA de la Generalitat de Cataluña 6/2011, de 5 de julio, que estiman que la acreditación de la solvencia es un soporte fundamental del sistema de selección del candidato para la adjudicación del contrato, permitiendo elegir las empresas más idóneas, y conseguir un pleno acierto en la elección de las mismas en beneficio del propio interés público que representa el órgano de contratación. La Resolución TACRC 33/2015, de 14-01-2015 señala, por su parte, y en este mismo sentido, que «la necesidad de garantizar al mismo tiempo el buen fin de los contratos a celebrar, permite a los órganos de contratación asegurarse de que el empresario que concurra a 
los artículos 77 y ss. LCSP). Destaca, en este punto y como tendremos ocasión de volver a analizar, como novedad más importante, la reducción de plazos en temas como la acreditación del volumen anual de negocios o la relación de obras ejecutadas avaladas por certificados de buena ejecución, así como la integración de la solvencia a través de medios externos.

Siguiendo con los requisitos exigidos por el art. 65 que hemos mencionado, es necesario que los licitadores no incurran en prohibición de contratar, prohibiciones que recoge el artículo 71 en una larga lista que no presenta carácter exclusivo. Por último, todos aquellos requisitos específicos que puedan venir requeridos por la normativa aplicable.

Estos requisitos, que podríamos decir, son requisitos generales de capacidad del empresario, persona física o jurídica que quiere contratar con las entidades del Sector Público, pretenden cumplir con una serie de principios, impuestos desde las Directivas comunitarias: el primero de ellos, el de libertad de concurrencia, que no es sino una particularidad del principio más genérico de igualdad y que persigue una doble finalidad. Por un lado, proteger los intereses económicos de los mismos y de las Administraciones, suscitando la máxima competencia posible; en segundo lugar, garantizar la igualdad de acceso a la contratación entre ellos. Se articula todo ello en una acción de conjunto cuyo objetivo es una modernización en profundidad del sistema público de contratación en la Unión Europea dentro de un contexto de globalización económica ${ }^{3}$, siendo uno de los ámbitos donde mejor se refleja la consolidación de este Derecho Administrativo global, precisamente, el de contratación pública. Esto mismo conlleva una cierta liberalización por parte de las Directrices que, como señalaremos, no cierra por completo todos los aspectos relativos a la contratación, en favor de objetivos de simplificación y eficiencia.

El principio de igualdad, la no discriminación, en general, vienen recogidos ya con carácter previo en la normativa comunitaria (desde los Tratados Fundacionales hasta el Derecho derivado actual y, más concretamente, en materia de contratos, las Directivas de contratos), pero también en nuestro propio texto fundamental a nivel interno. Vincula, incluso, a otros principios, como el de transparencia, así reconocido

la licitación reúna unas condiciones mínimas de solvencia, pero esas condiciones, que a tenor de lo dispuesto en la conocida STJUE dictada en el asunto "Succhi di Frutta" (Asunto C-496/99 P, Comisión de las Comunidades Europeas contra CAS Succhi di Frutta SpA) puede fijar libremente el órgano de contratación, deben ser especialmente respetuosas con los denominados principios comunitarios» (art. 74.2 LCSP, que exige que tales requisitos estén vinculados al objeto del contrato y ser proporcionales al mismo). Además de los principios de transparencia e igualdad de trato, base de las Directivas referentes a los procedimientos de adjudicación de los contratos públicos (Sentencias del TJUE Parking Brixen, de 13-10-2005, asunto C-458/03, y Sentencia Michaniki, de 16-12-2008, asunto C-213/07). Se puede consultar, MARTÍNEZ HELLÍN, J. (2011) "La adecuada determinación de los criterios de solvencia del contratista. Especial referencia al respeto a los principios de no discriminación e igualdad de trato" en El Consultor de los Ayuntamientos, núm. 15-16, pág. 1.872 y ss. Sobre la aplicación de los principios derivados del Derecho comunitario a los contratos públicos se puede consultar también MORENO MOLINA, J.A. (2006) Los principios generales de la contratación de las Administraciones Públicas, Bomarzo, Albacete; del mismo autor (2012) "El sometimiento de todos los contratos públicos a los principios generales de contratación", en el libro colectivo Liber amicorum Tomás-Ramón Fernández, Civitas-Thomson, Pamplona, pág. 3.492 y ss.; del mismo autor (2013) "La cuarta generación de Directivas de la Unión Europea sobre contratos públicos", en libro colectivo Observatorio de los Contratos Públicos 2012, Aranzadi, Cizur Menor, pág. 115 y ss.; GIMENO FELIÚ, J. M. ${ }^{a}$ (2013): "Las nuevas Directivas -cuarta generación- en materia de contratación pública. Hacia una estrategia eficiente en compra pública”, en Revista Española de Derecho Administrativo, núm. 159, pág. 39 y ss.; del mismo autor (2014) El nuevo paquete legislativo comunitario sobre contratación pública. De la burocracia a la estrategia. (El contrato público como herramienta de liderazgo institucional de los poderes públicos), Aranzadi, Cizur Menor; del mismo autor (2017), "La transposición de las directivas de contratación pública en España: una primera valoración de sus principales novedades", en Documentación Administrativa, DA. Nueva Época, núm. 4, pág. 7 y ss.; CARLÓN RUIZ, M. (2010) "El principio de proporcionalidad", en el libro colectivo Los principios jurídicos del Derecho Administrativo, La Ley, Madrid, en especial, pág. 209 y ss.; MEDINA ARNÁIZ, T. (2015) "La aplicación de las prohibiciones de contratar según la jurisprudencia del Tribunal de Justicia de la Unión Europea", en Observatorio de los Contratos Públicos, núm. monográfico especial sobre Las nuevas Directivas de Contratación Pública (Ponencias Sectoriales X Congreso Asociación Española Profesores de Derecho Administrativo), Thomson Reuters Aranzadi, primera edición, pág. 383 y ss.; CUNILLERA BUSQUETS, M. M. (2013) "A vueltas con los requisitos de solvencia en las licitaciones administrativas. La Sentencia del Tribunal de Justicia de la Unión Europea, de 18 de octubre de 2012”, en El Consultor de los Ayuntamientos, núm. 2, pág. 159 y ss.

3 En general, puede verse el estudio de SANTAMARÍA PASTOR, J. A. (2016) "Contratos del sector público y derecho de la Unión", en Revista de Administración Pública, núm. 200, pág. 83 y ss.; del mismo autor (2013), "La constante e interminable reforma de la normativa sobre contratación pública”, en Revista Española de Derecho Administrativo, núm. 159, pág. 25 y ss. MORENO MOLINA, J. A. (2018) "Globalización en el derecho de la contratación pública", en Estudios de Derecho Público en homenaje a Luciano Parejo Alfonso, vol. II, VAQUER CABALLERÍA, M., MORENO MOLINA, A. M. y DESCALZO GONZÁLEZ, A. (coords.), Tirant lo Blanch, pág. 1.743 y ss.; HUERGO LORA, A. (2005) "El Derecho español de contratos públicos y el Derecho comunitario", en Revista Española de Derecho Administrativo, núm. 126, pág. 217 y ss., quien afirma en la pág. 234 que «...las Directivas sobre contratación pública pretenden garantizar el cumplimiento de los principios de publicidad y concurrencia en la adjudicación de los contratos públicos, con independencia de las reglas aplicables a su ejecución, con independencia de que el contrato sea más o menos importante para el interés público y con independencia, también, de que se le califique como de Derecho Público o de Derecho privado...». 
tanto por la doctrina como por la jurisprudencia ${ }^{4}$. El principio de concurrencia, por su parte, está también vinculado al de igualdad y no discriminación, así como al de publicidad, puesto que a través de esta se garantiza que conozcan la existencia de los procedimientos de licitación el mayor número posible de licitadores y puedan presentar sus ofertas a los mismos. Implican que las condiciones y modalidades del procedimiento de licitación estén formuladas de forma clara, precisa e inequívoca en el anuncio de licitación o en el pliego de condiciones con el fin de que todos los licitadores razonablemente informados y normalmente diligentes puedan comprender su alcance, así como que la entidad adjudicadora pueda comprobar que todas las ofertas presentadas por los licitadores responden a los criterios exigidos para el contrato de que se trate ${ }^{5}$. Con ello se controla la imparcialidad en los procedimientos de adjudicación. La primera fórmula para conseguir cumplir con dichos principios es la publicación oficial a través, en primer lugar, del Perfil del Contratante, que tendrá que estar alojado en la Plataforma de Contratación del Sector Público o en páginas similares de las Comunidades Autónomas; en segundo lugar, a través de los Boletines Oficiales de los distintos Estados miembros de la Unión y, en algunos supuestos, a través del Diario Oficial de la Unión Europea. La transparencia también se puede canalizar a través del acceso a los distintos registros en los que deben inscribir los diferentes datos relativos a los contratos y los licitadores: el propio Registro de Contratos del Sector Público, el Registro Oficial de Licitadores y Empresas Clasificadas del Sector Público, o la Plataforma de Contratación del Sector Público, que aglutina toda la información recogida en los perfiles de contratación de las distintas Entidades del Sector Público.

Por otro lado, la LCSP crea, incluso, a estos efectos, un órgano encargado precisamente de promover la concurrencia, cual es la Oficina Independiente de Regulación y Supervisión de la Contratación (art. 332). Este organismo, adscrito orgánicamente al Ministerio de Hacienda, recibirá el texto de los contratos para examinarlos y valorar si existen prácticas incorrectas, reforzando con ello los principios a los que estamos haciendo alusión y previniendo supuestos de corrupción y/o clientelismo. Contribuye a esa prevención, que se permita a los interesados acceder a la documentación, siempre que no resulten perjudicados intereses públicos o privados legítimos, así como que este órgano pueda dictar instrucciones, aunque no tiene competencias de anulación o sanción.

\footnotetext{
${ }^{4}$ RAZQUÍN LIZARRAGA, M. M. ${ }^{a}$ (2018) "Los principios generales de la contratación pública”, en Tratado de Contratos del Sector Público, vol. I, GAMERO CASADO, E. y GALLEGO CÓRCOLES, I. (dirs.), ed. Tirant lo Blanch, Valencia, pág. 181 y ss., que cita Sentencia del TJUE 12-03-2015, asunto C-583/13, órgano jurisdiccional que afirma: «33. El principio de igualdad de trato entre los licitadores, que tiene por objetivo favorecer el desarrollo de una competencia sana y efectiva entre las empresas que participan en un contrato público, obliga a que los licitadores tengan las mismas oportunidades en la redacción de los términos de sus ofertas e implica, por lo tanto, que tales ofertas estén sujetas a los mismos requisitos para todos los licitadores» (y cita el propio Tribunal las Sentencias Comisión/CAS Succhi di Fruta, asunto C-496/99, apartado 10 y Cartiera dell'Adda, asunto C-42/13, apartado 14). Para seguir el propio Tribunal afirmando: «44. La obligación de transparencia, que constituye su corolario, tiene esencialmente como objetivo garantizar que no exista riesgo alguno de favoritismo y de arbitrariedad por parte del poder adjudicador respecto de determinados licitadores o de determinadas ofertas» (y vuelve a citar el Tribunal las mismas sentencias antes mencionadas). En la importante STJUE de 16 de septiembre de 2013 (Reino de España contra Comisión) el Tribunal afirma en su considerando 67 que «... el principio de igualdad de trato implica, en particular, una obligación de transparencia para permitir a la entidad adjudicadora garantizar su respeto (véanse las sentencias Lombardini y Mantovani (...) y Comisión/Chipre (...). El principio de transparencia, que constituye el corolario del principio de igualdad de trato, tiene esencialmente por objeto garantizar que no exista riesgo de favoritismo y arbitrariedad por parte de la entidad adjudicadora (sentencias Comisión /CAS Succhi di Frutta ...) y controlar la imparcialidad en los procedimientos de adjudicación (véase la sentencia Parking Brixen ...)». También se pueden citar las Sentencias del TJUE de 13-07-2017, asunto C-76/16, que matiza diciendo que el principio de igualdad, cuyo corolario es el de transparencia, «implica que todas las condiciones y la regulación del procedimiento de licitación estén formuladas de forma clara, precisa e inequívoca en el anuncio de licitación o en el pliego de condiciones, con el fin de que, en primer lugar, todos los licitadores razonablemente informados y normalmente diligentes puedan comprender su alcance exacto e interpretarlos de la misma forma y, en segundo lugar, el poder adjudicador pueda comprobar efectivamente que las ofertas de los licitadores responden a los criterios aplicables al contrato de que se trate», o la de 11-05-2017, asunto C-131/16, o la de 14-09-2017, asunto C-223/16, en la cual aporta otro dato revelador entre la relación de dichos principios y la posible negociación entre el poder adjudicador y el licitador, para rechazarla rotundamente: afirma que dichos principios «se oponen, en el marco de un procedimiento de adjudicación de un contrato público, a toda negociación entre el poder adjudicador y un licitador, lo que implica que, en principio, una oferta no pueda ser modificada después de su presentación, ni a propuesta del poder adjudicador ni del licitador. De ello se deduce que el poder adjudicador no puede solicitar aclaraciones a un licitador cuya oferta considere imprecisa o no ajustada a las especificaciones técnicas del pliego de condiciones». Por vulneración del principio de igualdad y no discriminación, el TACRC, en su Resolución 407/2017, de 05-05-2017, entiende que la exigencia impuesta en los pliegos para la conservación y mantenimiento de los jardines de un municipio de Alicante de que los posibles licitadores tengan inscrito en el Registro la huella de carbono, favorecería a las empresas residentes en España frente a las no residentes y, consecuentemente, anula dicho criterio recogido en los pliegos. Sobre el tema del arraigo territorial tendremos ocasión de volver también más adelante.

5 A ellos hace alusión el Acuerdo del TACP de Aragón 76/2013, de 17 de diciembre, cuando afirma que «el principio de transparencia, que constituye el corolario del principio de igualdad de trato, tiene como objeto garantizar que no exista riesgo de favoritismo y arbitrariedad por parte de la entidad adjudicadora ... y controlar la imparcialidad de los procedimientos de adjudicación» y cita las sentencias del TJUE Succhi di Fruta y Parking Brixen, ya aludidas.
} 
Igualdad, no discriminación, transparencia, concurrencia, se articulan para evitar uno de los males mayores contra los que lucha desde hace tiempo la Unión Europea, la corrupción en la contratación pública. Resulta significativo a este respecto un Informe de la Comisión al Consejo y al Parlamento europeo sobre la lucha contra la corrupción en la UE, de 3 de febrero de $2014^{6}$. Analizando el informe, y, teniendo en cuenta todo el procedimiento de contratación, se señala que dicha corrupción se puede producir antes de la licitación, durante la misma, o en la fase de ejecución. En la fase previa se señalan como defectos más destacados en estos aspectos que se analizan: 1 . El establecimiento de especificaciones a medida para favorecer a determinados licitadores; 2. La participación de los propios licitadores en el diseño de los pliegos; 3 . El establecimiento de criterios de selección poco claros y discriminatorios, criterios de selección que, por otra parte, los órganos de contratación tienden a confundir con los criterios de adjudicación (y que resulta reiteradamente desacreditado tanto por informes de las Juntas Consultivas como por Resoluciones de los Tribunales de Recursos Contractuales ${ }^{7}$ ); 4. El uso de criterios de selección injustificados y desproporcionados, entre otros. Al servicio de estos principios, otro que ahora se recoge en el art. $1 \mathrm{LCSP}$, el de integridad. De hecho, desde la perspectiva de este principio de integridad, la normativa comunitaria en materia de contratación pública se ha centrado fundamentalmente en la regulación de las fases de preparación y adjudicación de los contratos públicos con el fin de garantizar la transparencia en los procedimientos de adjudicación, la igualdad entre los licitadores y la apertura a la competencia de los procedimientos de adjudicación, sobre todo cuando los contratos superan determinados umbrales económicos.

Aquí podemos encontrar una de las justificaciones del estudio de esta materia en la páginas que siguen: partiendo del análisis particular de pliegos contractuales, podríamos decir que «a medida» de los licitadores, por lo menos en algunos casos, y de los informes de las Juntas Consultivas y Resoluciones de los Tribunales de Recursos Contractuales, veremos cómo estos órganos al analizar, bien los pliegos, bien los actos de exclusión de alguno de los candidatos, van perfilando las condiciones o requisitos que deben reunir estos y velan por que todo el procedimiento de contratación cumpla con todos los principios exigidos por la normativa nacional y comunitaria.

Otra de las cuestiones que pondremos de manifiesto en las páginas que siguen son los criterios medioambientales en la medida en que puedan servir para acreditar la experiencia de los posibles licitadores en estos aspectos. El art. 1.3 LCSP incorpora la obligación de tener en cuenta valores transversales relativos al valor social y ambiental, así como la protección a las PYMES, enmarcado en una acción positiva de las políticas públicas. Ya las Directivas 2004/17 y 2004/18 incorporaban consideraciones en torno a los

\footnotetext{
6 Ya se había elaborado una Comunicación previa, de 2011 sobre la lucha contra la corrupción que establecía la necesidad de elaborar este Informe. En general, se puede consultar GONZÁLEZ SANFIEL, A. M. (2015) "Integridad en la contratación pública: Patologías al uso. A propósito del informe de la Comisión Europea sobre lucha contra la corrupción", en Observatorio de los Contratos Públicos, núm. monográfico especial sobre Las nuevas Directivas de Contratación Pública (Ponencias sectoriales X Congreso Asociación Española Profesores de Derecho Administrativo), Thomson Reuters Aranzadi, primera edición, pág. 253 y ss.; CERRILLO I MARTíNEZ, A. (2018) El principio de integridad en la contratación pública: mecanismos para la prevención de los conflictos de intereses y la lucha contra la corrupción, Thomson Reuters Aranzadi, 2. ${ }^{a}$ edición. Es significativo este autor cuando afirma, pág. 58 que «Los numerosos y reiterados casos de corrupción de los que dan noticia los medios de comunicación en el ámbito de la contratación pública nos indican que este es un ámbito propenso a la proliferación de prácticas corruptas. De hecho, la mayoría de los principales casos de corrupción juzgados en los últimos años en España han estado ligados a la contratación pública». Véase también GIMENO FELIU, J. M. (2017), "Medidas de prevención de corrupción y refuerzo de la transparencia en la contratación pública", en REALA. Nueva Época, núm. 7 , pág. 45 y ss., que analiza, entre otros extremos, la importancia de la aplicación de los principios de integridad y transparencia a la contratación pública, así como el papel de la recién creada Oficina Independiente de control y supervisión de la contratación pública y de prevención de la corrupción. Sobre este tema, véase también TEJEDOR BIELSA, J. (2018), La contratación pública en España ¿Sobrerregulación o estrategia? Causas y consecuencias de su problemática aplicación, Thomson Reuters Proview, Navarra, quien afirma, por ejemplo, en la pág. 21 que «La LCSP responde a dos principios no explícitos, que explican también parte de su contenido y que, en cierto modo, tienen su origen en dos prejuicios, la presunción de una corrupción generalizada, agravada por un ambiente social, económico y político tóxico, y la concepción de lo público como mera traba administrativa a la eficiencia del mercado». En particular, sobre la transparencia, pág. 124 y ss. De la lucha contra la corrupción y el papel que pueden tener las prohibiciones para contratar en este aspecto, se ocupa MEDINA ARNAIZ, T. (2018), Las prohibiciones de contratar desde una perspectiva europea, Thomson Reuters Aranzadi, Navarra, primera edición.

7 Ya el TJUE había diferenciado estas dos cuestiones, los criterios de selección y los criterios de adjudicación (a ello nos referiremos también posteriormente). Los criterios de selección cualitativa tienen por cometido la comprobación de la aptitud de los licitadores que es llevada a cabo por las entidades adjudicadoras con arreglo a la capacidad económico, financiera y técnica o profesional, mientras que los criterios de adjudicación están relacionados, ahora, con la oferta económicamente más ventajosa en relación con el objeto del contrato. SSTJUE de 24 de enero de 2008, Linakis, asunto C-532/06, apartado 27; 18 de diciembre de 2014, Ambisig, asunto C-601/03; de 1 de marzo de 2018, Tirkkonen, asunto C-9/17, apartado 36. Así lo hizo también el TACRC en sus Resoluciones 220/2012, de 3 de octubre; 290/2012, de 14 de diciembre y 361/2017, de 21 de abril.
} 
objetivos ambientales en el régimen de contratación pública. La contratación pública sostenible y la compra verde forman parte de las principales políticas europeas como se refleja, por ejemplo, en la Estrategia de la Unión Europea para un Desarrollo Sostenible de 2008.

En el nuevo paquete normativo, concretamente en la Directiva 2014/24 se amplían las consideraciones sobre los criterios ambientales ${ }^{8}$, fomentando alternativas sostenibles a los productos y servicios ofrecidos hasta ese momento. Ya su art. 18.2 había dejado establecido que «los Estados miembros tomarán las medidas pertinentes para garantizar que, en la ejecución de los contratos públicos, los operadores económicos cumplen las obligaciones aplicables en materia medioambiental, social o laboral, establecidas en el Derecho de la Unión, el Derecho nacional, los convenios colectivos o por las disposiciones del Derecho Internacional medioambiental, social y laboral enumeradas en el anexo X».

La Estrategia Europa $2020^{9}$ resalta igualmente la contratación pública verde para conseguir un crecimiento inteligente, sostenible e integrador y conseguir una mayor eficiencia en el gasto de los fondos públicos.

Estos criterios ambientales también tienen que estar vinculados con el objeto del contrato y resultar acordes con el principio de proporcionalidad ${ }^{10}$, permitiendo medios de prueba alternativos equivalentes. Así la Directiva de 2014 se refiere al sistema comunitario de gestión y auditoría medioambiental (EMAS) o a otros sistemas de gestión medioambiental reconocidos ${ }^{11}$ y que son incorporados a nuestra LCSP.

Una cuestión que se ha planteado también a nivel de pliegos de contratación y que luego resolvieron nuestros órganos contractuales, fue que dichos pliegos exigían los requisitos ambientales bien como criterio de solvencia bien como criterio de adjudicación. En el primer caso, se estaría incluyendo un obstáculo de entrada impidiendo que aquellas empresas que no reúnan estos requisitos no pudieran presentarse a la licitación. En el segundo supuesto, cualquier empresa podría presentarse a la licitación y los poderes adjudicadores podrán elegir la oferta que más convenga desde el punto de vista económico y que incluya también la mejor calidad ambiental. Esto afectaría fundamentalmente a la desproporción que en algunos pliegos puede presentarse respecto a las exigencias de estos requisitos medioambientales, porque, efectivamente, algunos van a exigir unos requisitos de solvencia muy desproporcionados en relación con los necesarios para la ejecución del contrato ${ }^{12}$.

Sabemos, además, que la falta de estos requisitos mencionados son causas de nulidad de derecho administrativo del contrato de acuerdo con el art. 39.2.a) LCSP, sin perjuicio de lo cual si la declaración administrativa de nulidad de un contrato produjese un grave trastorno al servicio público podrá disponerse en el propio acuerdo la continuación de los efectos del contrato bajo las mismas cláusulas hasta que se adopten las medidas urgentes necesarias para evitar el perjuicio (art. 42.3 LCSP). Y que las circunstancias relativas a la capacidad, solvencia y ausencia de prohibiciones de contratar deberán concurrir en la fecha final de

8 LÓPEZ TOLEDO, P. (2014) "La contratación pública verde y su nueva regulación en el Derecho de la Unión Europea”, en Contratación Administrativa Práctica, núm. 134, pág. 15 y ss.; GIMENO FELIÚ, J. M. ${ }^{\text {a }}$ (2013), "Novedades en la nueva normativa comunitaria sobre contratación pública", en Revista de Estudios Locales, núm. 161, pág. 15 y ss. Del mismo autor, (2013) "Las nuevas Directivas -cuarta generación- en materia de contratación pública. Hacia una estrategia eficiente en compra pública", op. cit.; SARASÍBAR IRIARTE, M. (2015) "La contratación pública se tiñe de verde", en Observatorio de los Contratos Públicos, núm. monográfico especial sobre Las nuevas Directivas de Contratación Pública (Ponencias sectoriales X Congreso Asociación Española Profesores de Derecho Administrativo), Thomson Reuters Aranzadi, primera edición, pág. 317 y ss.; MORENO MOLINA, J. A. (2014) "La nueva Directiva sobre contratación pública y su incorporación al Derecho español”, en Contratación Administrativa Práctica, núm. 129, pág. 16 y ss.

${ }_{9}$ Señala el crecimiento inteligente, sostenible e integrador como manera de superar las deficiencias estructurales de la economía europea, mejorar su competitividad y productividad y sustentar una economía social de mercado sostenible.

10 PERNAS GARCÍA, J. J. (2014) "La dimensión ambiental en la normativa de contratos del sector público", vol. Colectivo de FERNÁNDEZ ACEVEDO, R. y VARCÁRCEL FERNÁNDEZ, P. (Directores), titulado La contratación pública a debate: presente y futuro, Thomson Reuters, Cizur Menor, pág. 345 y ss.; GALLEGO CÓRCOLES, I. (2014) "Aplicación de medidas de gestión medioambiental como requisito de acreditación de solvencia técnica”, en Contratación Administrativa Práctica, núm. 134, pág. 53 y ss.

11 EI TACRC, en la Resolución al recurso 126/2012, de 20-09-2012 permitió que se utilizasen, incluso, otros certificados si no se podía acceder a los exigidos por la normativa y el licitador demostraba la equivalencia a los certificados exigidos. En el mismo sentido Resolución al recurso 490/2013, de 20-09-2013, donde afirma que «la acreditación del cumplimiento de los sistemas de gestión ambiental puede serlo mediante los tales certificados "o equivalentes", siendo así que, con arreglo a dicha expresión, deberán reconocerse como válidos los certificados equivalentes emitidos por organismos establecidos en cualquier Estado miembro de la Unión Europea y aceptarse cualesquiera otras pruebas equivalentes de medidas de gestión medioambiental o de garantía de la calidad que presenten los licitadores». Sentencia del TSJ Valencia 07-05-2005 (recurso 1082/2005), que exige que el certificado de gestión ambiental exigido esté relacionado con el objeto del contrato. El respeto al principio de proporcionalidad se exige, por ejemplo, en Resoluciones del TACRC de 16-02-2011 (recurso 14/2011), 11-10-2012 (recurso 209/2012).

12 Por ejemplo, en la Resolución del TARC de Madrid 113/2014, de 09-07-2014, se afirma que los requisitos mínimos de solvencia que ha de reunir el empresario deben estar vinculados con el objeto del contrato y ser proporcionados al mismo para así garantizar el libre acceso de las empresas a la licitación pública, la igualdad de trato y la máxima concurrencia. 
presentación de ofertas ${ }^{13}$ y subsistir en el momento de perfección del contrato, de acuerdo con el art. 140.4 LCSP. Momento de la perfección que será el de formalización del contrato (art. 36.1 LCSP). Por su parte, el art. 40.2.b) LCSP permite presentar recurso especial en relación con la decisión de la mesa o del órgano de contratación de admitir o inadmitir un licitador por incumplimiento de estas circunstancias ${ }^{14}$.

\section{LA SOLVENCIA TÉCNICA Y PROFESIONAL. EL REQUISTO DE LA EXPERIENCIA}

Pero habíamos dicho que nos centraríamos en los aspectos relativos a la solvencia técnica y profesional. Con estos términos se hace referencia a un conjunto de requisitos de idoneidad que debe poseer cualquier posible contratista para atender el objeto del contrato de una forma adecuada y hace referencia, también, a los medios técnicos y humanos con que se cuenta, la experiencia previa, la competencia técnica y profesional, la habilidad necesaria, la cualificación profesional de su personal. Se exige a todos los licitadores en la fase de selección del contratista y tiene que tener relación con el objeto del contrato y las especificaciones técnicas incluidas en los pliegos y ser proporcionado al mismo. A este requisito, junto al de solvencia económica y financiera se refiere el art. 74.1 de la LCSP cuando afirma que «para celebrar contratos con el sector público los empresarios deberán acreditar estar en posesión de las condiciones mínimas de solvencia económica y financiera y profesional o técnica que se determinen por el órgano de contratación. Este requisito será sustituido por el de la clasificación, cuando esta sea exigible conforme a lo dispuesto en esta Ley».

El requisito de la solvencia técnica-profesional (y dentro de él, la exigencia de experiencia a los licitadores) no está armonizado en la UE, lo que deja un amplio margen a los poderes adjudicadores. El art. 58 de la Directiva 2014/24/UE al regular los criterios de selección y referirse a la solvencia técnica y profesional, establece que «los poderes adjudicadores podrán imponer requisitos para asegurar que los operadores económicos poseen la experiencia y los recursos humanos y técnicos necesarios para ejecutar el contrato con un nivel adecuado de calidad», que podrán exigir, en particular, que «los operadores económicos tengan un nivel suficiente de experiencia demostrada mediante referencias adecuadas de contratos ejecutados en el pasado» y que «en los procedimientos de contratación de suministros que requieran operaciones de colocación o instalación, servicios u obras, la capacidad profesional de los operadores económicos para prestar dichos servicios o ejecutar la instalación o las obras podrá evaluarse teniendo en cuenta sus conocimientos técnicos, eficiencia, experiencia y fiabilidad». Y cierra el artículo autorizando a los poderes adjudicadores a que indiquen «las condiciones exigidas para la participación, que podrán expresarse como niveles mínimos de capacidad, así como el medio de prueba adecuado, en el anuncio de licitación o en la invitación a confirmar el interés». Por su parte el art. 60.1 de la Directiva deja entrever que el órgano de contratación tiene un amplio margen de apreciación para elegir los medios de prueba, aunque luego se remite a los recogidos en el Anexo XII.

La LCSP, en el mismo sentido, deja margen de apreciación al órgano de contratación, pero de entre los requisitos recogidos en los arts. 88 a 91, que distinguen, en lo que a solvencia técnica o profesional se refiere, entre la que se exige para los contratos de obras (art. 88), contrato de suministro (art. 89), contrato de servicios (art. 90), u otro tipo de contratos (art. 91). No es que sean, tampoco, tan diferentes de los recogidos en el TRLCSP ${ }^{15}$, excepto, quizás, en una mayor concreción de la competencia, permitiendo

13 La distintas Juntas Consultivas de Contratación venían interpretando tradicionalmente que los requisitos de aptitud debían cumplirse en el momento en que finaliza el plazo de presentación de ofertas, independientemente de que el licitador la hubiera presentado con anterioridad a la finalización de dicho plazo. Por su parte el TACRC, en su Resol. 308/2012, de 28-12-2012, analiza un supuesto de revocación de clasificación que se produce antes de la adjudicación y concluye que estos requisitos de aptitud se tendrían que dar tanto en el momento de la licitación (momento de presentación de la oferta) como en el momento de la perfección del contrato administrativo. Decisión acertada y evidente que ahora hace suya ese párrafo 4 del art. 140 LCSP cuando añade que debe «subsistir en el momento de perfección del contrato».

14 STJUE de 5 de abril de 2017, C-291/2015, pone en tela de juicio la anterior normativa española de contratos que no permitía presentar recurso especial en estos supuestos.

15 Ya por entonces, la JCCAE en su Informe 36/07, de 5 de julio, señalaba que los medios de acreditación de la solvencia que fijara el órgano de contratación deberían cumplir una serie de requisitos: que figuraran en el pliego de cláusulas administrativas particulares y en el anuncio del contrato; que sean determinados; que estén relacionados con el objeto y el importe del contrato; que se encuentren entre los enumerados en la Ley en función del tipo de contrato y, por último, que no produzcan efecto discriminatorio, sin que pueda identificarse la discriminación con que unos licitadores puedan cumplir con las exigencias establecidas y otros no. En parecidos o idénticos términos, encontramos las más recientes Resoluciones del TACRC 715/2016, de 16 de septiembre; $597 / 2017$, de 30 de junio; 362/2018, de 13 de abril; 464/2018, de 11 de mayo; o la 713/2018, de 27 de julio. 
que PYMES y empresas de nueva creación accedan con más facilidad a los procedimientos de licitación, rebajando los plazos necesarios, como señalaremos, para acreditar la experiencia previa [arts. 88.1.a); 89.1.a) y 90.1.a) LCSP].

En la regulación anterior, con el Texto Refundido de la Ley de Contratos del Sector Público de 2011 (arts. 62 a 64 y 74 a 82) y el desarrollo de esta cuestión a través del artículo 11 del Reglamento General de la Ley de Contratos de las Administraciones Públicas ${ }^{16}$, la acreditación de la experiencia resultaba un auténtico calvario en ocasiones para, fundamentalmente, las pequeñas y medianas empresas, máxime si tenemos en cuenta los artículos 58 y siguientes de la Directiva 2014/24 que, con un efecto directo, relajaban notablemente los requisitos a favor de una mayor aplicación del principio de concurrencia entre los posibles licitadores, por ejemplo en el período de tiempo a tener en cuenta para acreditar la experiencia en contratos similares ${ }^{17}$.

Quiero destacar en este momento un problema jurídico que plantea el tema relativo a la experiencia que estamos analizando. El art. 44. tres de la Ley 14/2013, de 27 de septiembre, de apoyo a los emprendedores y su internalización introdujo una nueva letra d) en el art. 32 TRLCSP, creando un nuevo supuesto de nulidad de pleno derecho de los contratos públicos y sus actos preparatorios. De acuerdo con dicha redacción, serían causas de nulidad de derecho Administrativo, «d) Todas aquellas disposiciones, actos o resoluciones emanadas de cualquier órgano de las Administraciones Públicas que otorguen, de forma directa o indirecta, ventajas a las empresas que hayan contratado previamente con cualquier Administración». Sin embargo, dicho apartado desaparece de la nueva redacción de la LCSP, pasando al art. 40, pero como causa de anulabilidad de Derecho Administrativo con una redacción similar: «todas aquellas disposiciones, resoluciones, cláusulas o actos emanados de cualquier Poder Adjudicador que otorguen, de forma directa o indirecta, ventajas a las empresas que hayan contratado previamente con cualquier Administración».

Ahondando más aún en esa eliminación de ventajas discriminatorias, el art. 45 de la Ley 14/2013 establece también que «en sus procedimientos de contratación, los entes, organismos y entidades integrantes del sector público no podrán otorgar ninguna ventaja directa o indirecta a las empresas que hayan contratado previamente con cualquier Administración».

Y la cuestión es que estos artículos no han sido derogados expresamente. ¿Cómo conciliarlo con la nueva redacción de la LCSP? Evidentemente, la LCSP es posterior en el tiempo y habría que aplicar la derogación genérica de cuantas disposiciones de igual o inferior rango se opongan a la misma para encontrar la solución. Pero el cambio de criterio plantea otro problema y es que el regularlo como causa de nulidad o anulabilidad tiene sus diferencias, puesto que la nulidad de pleno derecho produce una serie de efectos (art. 42 LCSP) que puede declarar la propia Administración en un procedimiento de revisión de oficio, mientras que los mismos efectos ante un supuesto de anulabilidad solo pueden ser declarados en la sentencia que ponga fin a un procedimiento contencioso-administrativo interpuesto previa declaración de lesividad de conformidad con el art. 71 de la LJCA. Si lo que se quería era incorporar a la LCSP los criterios favorecedores que la Ley de emprendedores de 2013 había introducido, esto supone, evidentemente, un retroceso.

16 Real Decreto 1098/2001, de 12 de octubre, por el que se aprueba el Reglamento de la Ley de Contratos de las Administraciones Públicas, modificado por el Real Decreto 773/2015, de 28 de agosto, que continuará en vigor en todo lo que no contradiga lo dispuesto en la LCSP.

17 Respecto a dicho margen temporal, y antes de la reducción experimentada en la redacción actual de la Ley de Contratos del Sector Público, el Informe 17/2013, de 26 de junio, de la JCCA de la Comunidad de Aragón, en previsión de la redacción que después tendría la Directiva 2014/24 ya afirmaba que «... dentro de esta libertad de configuración, y desde una interpretación sistemática y funcional del actual TRLCSP, puede concluirse que los plazos de cinco y tres años previstos en los artículo 76.a), 77.a) y 78.a) pueden modularse-siempre que sea necesario para garantizar un nivel adecuado de competencia y concurrencia-, ampliándolos, atendiendo a las circunstancias concretas de cada licitación». En este párrafo transcrito habla de ampliación, pero ya antes había hablado de que los poderes adjudicadores no podían verse limitados por los plazos, ni como mínimo ni como máximo y en este párrafo en concreto se habla de la libertad de configuración del órgano, lo que nos induce a pensar que, sin ningún problema, también pueden reducirse dichos plazos. Por otro lado, en el Informe de la Junta Consultiva de Contratación Administrativa del Estado 5/2006, de 24 de marzo de 2006, en sus conclusiones plantea «1. Que la expresión últimos años que utilizan los artículos 17 b), 18.a) y 19.b) de la Ley de Contratos de las Administraciones Públicas deber ser interpretada en el sentido de comprender el mismo año de la convocatoria de licitación» y «2. Que, no obstante, para ello es preciso que el contrato se haya ejecutado, sin que sea suficiente la adjudicación» (se gana en plazo por la primera conclusión, pero es más severa la segunda). Sin embargo, en relación con esta segunda conclusión, el TACRC en su resolución 1157/2015, recurso 1198/2015, realiza una interpretación más favorable, ya que considera suficiente la adjudicación del contrato público para acreditar la solvencia, «siendo razonable la interpretación del órgano de contratación de que lo relevante es el importe adjudicado, y no lo facturado, pues es lo adjudicado lo que muestra la entidad del contrato, acreditativa de la capacidad del licitador». 
La experiencia, exigida como forma de acreditación de la solvencia de los empresarios, ha sido rechazada en varias ocasiones por el propio TS por resultar contraria al principio de libre competencia ${ }^{18}$. De esta forma lo que se estaría haciendo es favorecer a aquellos licitadores que hubieran prestado servicios previamente a cualquier Administración. Ello no quiere decir, necesariamente, que con esa experiencia previa el licitador no pueda demostrar que puede cumplir mejor el objeto del contrato, pero nada impide que el licitador que no la tenga, no pueda cumplirlo exactamente igual o mejor.

Efectivamente, en numerosas ocasiones nuestro alto Tribunal reconoce que la valoración de la experiencia supone la contravención del principio de libre competencia en la contratación administrativa, así como de las directrices en materia de contratación de la Unión Europea, por lo que no debería ser consignado este requisito en los Pliegos de Condiciones Particulares, procediendo a anularse tanto pliegos de condiciones como acuerdos de adjudicación ${ }^{19}$.

Por su parte, el TACRC, en su Resolución 207/2014, de 14 de marzo, analizaba un requisito de solvencia que consistía en haber sido adjudicataria de al menos tres contratos adjudicados por Ayuntamientos de más de 20.000 habitantes, por alguno de los procedimientos indicados en el artículo 138 del Real Decreto Legislativo 3/2011 (abierto, restringido, negociado, diálogo competitivo y el específico para el concurso de proyectos), a excepción de los contratos menores que no se tendrán en consideración a estos efectos, cuyo objeto sea similar al que allí se valoraba ${ }^{20}$. La cláusula se eliminó por desproporcionada, al igual que en el Acuerdo 9/2014, de 11 de febrero, del Tribunal Administrativo de Contratos Públicos de Aragón, que aplica, en este caso, el art. 45 de la Ley 14/2013, de apoyo a los emprendedores.

No resulta descabellado pensar que tal especificación en los requisitos de experiencia exigidos a los licitadores es porque la Administración que licita el contrato quiere contar con el mismo o similar contratista, que no se pone en duda puede ser porque el objeto del contrato se realizó correctamente, pero también induce a pensar en intereses no tan loables. Precisamente la corrupción en materia de contratación es uno de los argumentos aducidos para las modificaciones que ha sufrido este sector de nuestro ordenamiento jurídico, tanto a nivel nacional como comunitario, normativa que ha apostado claramente por una mayor apertura del mercado a cuantos más oferentes mejor, para conseguir mejoras en las condiciones de contratación y nada impediría pensar que quien no reúna características tan específicas de experiencia no pueda realizar su cometido igual o mejor que quien sí las cumpla.

Consecuentemente, habrá que seguir entendiendo que los entes, organismos y entidades integrantes del sector público, no podrán otorgar ventajas directas o indirectas a las empresas que previamente hayan contratado con cualquier Administración, de acuerdo a lo establecido en el art. 45 de la Ley de emprendedo-

18 SSTS de 07-06-2012, 4371/2012, donde puede leerse en su F. J. 4. ${ }^{\circ}$ que «... esta Sala viene declarando reiteradamente que la valoración de la experiencia contraviene el principio de libre competencia para la contratación administrativa que rige en nuestro Derecho de conformidad con lo dispuesto en la normativa de la hoy Unión Europea...». Así lo recuerda la sentencia de 11 de julio de 2006 (Casación 410/2004 ), que se expresa así: «(...) este Tribunal en su sentencia de 24 de mayo de 2004, recurso de casación 7759/1999, ha sostenido que la valoración de la experiencia supone la contravención del principio de libre competencia en la contratación»; o en las de 16-02-2010, 1047/2010; de 21-03-2007, 2307/2007, por ejemplo.

19 Así pasaba en una sentencia de 10 de mayo de 2004, recurso de casación 44/1999 (RJ 2004/3495), donde el TS desestima el recurso de casación interpuesto por un Ayuntamiento frente a sentencia dictada por la Sala de lo Contencioso-Administrativo del Tribunal Superior de Justicia de Canarias que anulaba el pliego de condiciones económico administrativas y el acuerdo de adjudicación de un concurso impugnado por un licitador dado que se exigía una experiencia mínima de tres años en la gestión de los servicios municipales de abastecimiento de agua potable, lo que infringía el principio de libre concurrencia ya establecido en el art. 13 de la Ley de Contratos del Estado de 1965. Pero se pueden citar muchas más: SS 25-09-2000 (casación 7065/1994; RJ 2000, 8416); 24-05-2004 (casación 7759/1999 (RJ 2004/413); 28-02-2005 (casación 161/2002; RJ 2005/3453); 23-03-2005 (casación 2129/2002; RJ 2005, 3460); 28-042005 (casación 418/2003; RJ 2005/4702); 24-01-2006 (casación 7645/2000, RJ 2006/2726).

20 Como señala HUERGO LORA, A. (2017) "La experiencia como requisito para contratar con el sector público y sus límites Casos recientes", en la página web http://estudiojuridicoip.com/la_experiencia_requisito_solvencia_tecnica_profesional_contratos_sector_publico_limites_casos_recientes/, pág. 3, la cláusula se ānuló entendiendo que era desproporcionada. En la resolución del Tribunal se afirmaba que «la concreta exigencia de un número de contratos de objeto similar celebrados con Ayuntamientos de más de 20.000 habitantes, en concreto tres, formulada con carácter absoluto, sí que afecta a la libre concurrencia y produce el efecto de restringir de modo desproporcionado el acceso a la licitación. Desde luego, la cifra de 20.000 habitantes es razonable y justificada, al ser, no sólo el segmento de población en que se sitúa el municipio licitador, que cuenta con más de 31.000 habitantes, sino porque se trata de uno de los umbrales que para la prestación de servicios se contempla en la Ley de Bases de Régimen Local, artículo 26. C)». Sin embargo, entiende que una exigencia tan detallada «excluye, de forma definitiva a quienes no reúnan dicho requisito, convirtiendo, de hecho, esta exigencia en una especie de clasificación, de modo que, quien no la tenga no podrá acceder a los contratos, que quedan reservados para quien cumpla este requisito. Debiendo señalarse, por otro lado, que si se cumple este requisito es porque, en alguna licitación, por vez primera, no se le exigió, lo cual encierra, en cierto modo, sobre una incongruencia, una discriminación». 
REALA. Nueva Época - N.o 12, octubre-marzo 2019 - ISSN: 1989-8975 - DOI: 10.24965/reala.i12.10706 - [Págs. 26-51]

Los requisitos de solvencia técnica-profesional. La experiencia

Asunción Nicolás Lucas

res de 2013, aunque el hacerlo será ahora con la nueva LCSP determinante de anulabilidad y no de nulidad de pleno derecho de los contratos públicos y sus actos preparatorios.

\section{LOS REQUISITOS DE SOLVENCIA COMO CRITERIOS DE SELECCIÓN}

Los requisitos de solvencia desde el punto de vista que los analizamos en estas páginas, serán estudiados como criterios de selección, sin que nos detengamos a analizar su posible aplicación en la adjudicación del contrato, fases distintas en el procedimiento de contratación y que ya el propio TJUE había distinguido, constituyendo los criterios de selección una fase de carácter previo que, superada, permitiría entrar en la fase de valoración y adjudicación ${ }^{21}$. La solvencia hace referencia a las características de las empresas licitadoras que les permitirían presentarse a la licitación de los contratos. Los criterios de adjudicación ${ }^{22}$ se refieren concretamente al contenido de la oferta, que tiene que ver más específicamente con el objeto del contrato.

Como sabemos, además, estos criterios de selección están íntimamente relacionados con la capacidad de obrar, la habilitación económica o profesional, la solvencia económica, y las prohibiciones para contratar. Quiero aclarar en este momento que, aunque la identidad de términos puede hacer similares la habilitación y la solvencia técnica-profesional, en el primer caso se hace referencia a la aptitud legal para ejercer una profesión, actividad o prestación, que serán luego las que se oferten a las entidades del sector público para la realización del objeto del contrato. Los requisitos de habilitación afectan más bien a la capacidad de obrar, porque acreditan la aptitud legal para el ejercicio, y cumple, por lo tanto, una finalidad distinta de los criterios de solvencia, ya que esta se refiere a la condición para ser parte en un procedimiento de licitación ${ }^{23}$. Evidentemente será un requisito mínimo que deberá reunir previamente la persona física o jurídica que quiera contratar con alguna entidad del sector público y no será exigible para toda profesión, actividad o prestación que se realice, porque ello dependerá de la normativa sectorial aplicable. Pero será diferente de la solvencia técnica o profesional que se exigirá al empresario para la realización del concreto contrato que se licita y que, en función del objeto del mismo, nos hace pensar que dichos requisitos de solvencia pueden resultar perfectamente superiores a los exigidos por la normativa de habilitación profesional.

21 JCCA del Estado, Informes 53/1997, de 02-03-1998; 36/2001, de 09-01-2002; 45/2002, de 08-02-2003, que hace suya la doctrina del TJUE. El informe 36/2001 afirma que «la JCCA ha sentado los criterios, siguiendo fundamentalmente la doctrina de la sentencia del Tribunal de Justicia de las Comunidades Europeas de 20 de septiembre de 1988 (asunto C 31/1987 - "Beentjes"), de que en los procedimientos de adjudicación de contratos hay que considerar fases distintas, con requisitos también distintos, la de selección de los contratistas y la de adjudicación del contrato, distinción recogida en la Ley de Contratos de las Administraciones Públicas, al referirse a la primera fase los artículos 15 a 19 y la segunda el art. $86 \ldots$ sin que los criterios de selección, entre ellos la experiencia, pueda ser utilizado como criterio de adjudicación ...». Por su parte, el informe 45/2002, mencionado, afirma literalmente que «el Tribunal de Justicia de las Comunidades Europeas (TJUE) advierte que, en el procedimiento de adjudicación de un contrato existen dos fases claramente diferenciadas. En la primera se procede a la valoración cualitativa de las empresas candidatas mediante el examen de los medios que han de disponer para la ejecución del contrato (solvencia) y después, respecto de las admitidas en tal fase, se procede a la valoración de las ofertas que cada una de ellas ha presentado y, en tal sentido, señala que se trata de operaciones distintas y regidas por normas diferentes». Se puede acudir también a la STJUE de 19 de junio de 2003, GAT, asunto C315/01; de 24 de enero de 2008, Lianakis, asunto C-532/06; de 10 de octubre de 2013, Swn Costruzioni, asunto C-94/12; de 10 de julio de 2014, Consorcio Stabile Libor Lavori Pubblici, asunto C-385/12, apartado 31 y Sentencia de 23 de diciembre de 2009, Serrantoni, asunto C-376/08, apartado 44. Se puede consultar, haciéndose eco de esta misma doctrina, GARCÍA SANTOS, J. y JURADO JIMÉNEZ, J. C. (2018), "Aptitud para contratar con el sector público. Capacidad y solvencia del empresario", en Tratado de Contratos del Sector Público (GAMERO CASADO, E. y GALLEGO CÓRCOLES, I., (dirs.), vol. II, ed. Tirant lo Blanch, Valencia, pág. 1.043 y ss. En general, sobre la solvencia, VÁZQUEZ MATILLA, F. J. (2018), "La solvencia en la nueva LCSP", en Estudio sistemático de la Ley de contratos del sector público (coord. GIMENO FELIU, J. M),

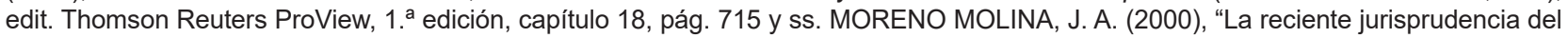
Tribunal de Justicia de las Comunidades Europeas en materia de contratos públicos", en Revista de Administración Pública, núm. 151, pág. 319 y ss.; RAZQUIN LIZARRAGA, M. M. ${ }^{a}$ (2000), "La jurisprudencia del Tribunal de Justicia de las Comunidades Europeas sobre contratación pública", en Justicia administrativa, núm. 6, pág. 5 y ss.; del mismo autor (2015), "Las nuevas Directivas sobre contratación pública de 2014: aspectos clave y propuestas para su transformación en España”, en Revista de Administración Pública, núm. 196, pág. 97 y ss.; MORENO MOLINA, J. A. y DOMÍNGUEZ ALONSO, A. P. (2014), "El nuevo derecho de la Unión Europea sobre contratación pública", en el libro colectivo La contratación pública a debate: presente y futuro, Civitas-Thomson, Cizur Menor, pág. 139 y ss.; CHINCHILLA MARÍN, C. (2011) "La jurisprudencia del TJUE sobre contratos públicos (I). Ámbito subjetivo y objetivo de aplicación de las Directivas" en El Derecho de los contratos públicos en la Unión Europea y sus Estados miembros, Lex Nova, Valladolid, pág. 33 y ss.

${ }^{22}$ Aunque nada impediría que pudieran establecerse criterios semejantes. STS de 21 marzo 2007, RJ 2007/4044.

23 De acuerdo con la Resolución TACRC 366/2016, de 13-05-2016, el título habilitante a que se refiere el art. 65 LCSP se configura como requisito de legalidad y no de solvencia en sentido estricto. Diferencian ambos conceptos también la Resolución 40/2013, de 6 de marzo, del TACPCM; la 279/2016, de 4 de noviembre, del TARCJA; la 465/2016, de 17 de junio, del TACRC. Así como por varios informes de la JCCA del Estado, 1/2009, de 25 de septiembre; 6/2010, de 21 de diciembre, de la de Madrid. 
Como ya hemos señalado anteriormente, la referencia a estas cuestiones se realiza ahora en el art. 74 LCSP (equivalente art. 62 TRLCSP), con un amplio margen de apreciación a favor del órgano de contratación, aunque con una serie de límites que hacen referencia a la necesidad de que se especifiquen en el pliego del contrato; el criterio de proporcionalidad; y la vinculación al objeto del contrato.

Esta regla de la proporcionalidad ha planteado numerosos conflictos ${ }^{24}$, afecta directamente a la libre concurrencia como principio aplicable a la contratación pública, y la aplicación de la misma permitiría que los empresarios solventes puedieran acudir libremente a la licitación. Todo lo contrario, es decir, exigir unos requisitos desproporcionados impediría que pudieran presentarse algunos empresarios que no reúnen los requisitos exigidos en los pliegos pero que, sin embargo, son plenamente solventes y hubieran podido dar cumplimiento al objeto del contrato sin ningún tipo de problema.

Respecto a este requisito de la proporcionalidad, son significativas algunas Resoluciones de nuestros Tribunales de Recursos Contractuales. En una Resolución TARCJA 237/2015, de 07-07-2016, se planteaba el requisito de exigir 44 idiomas para acreditar la solvencia a los licitadores, resolviendo el Tribunal que «si bien es cierto que el adjudicatario debe estar en condiciones de ejecutar el objeto del contrato en todos los idiomas incluidos en el Anexo II del PPT, como así se establece en éste, este Tribunal considera desproporcionado que se requiera la acreditación de todos ellos como requisito previo de solvencia, ya que a nuestro juicio infringe el principio de libre concurrencia, motivo por el que deberá ser modificado. Por ello, este Tribunal considera que debería limitarse la acreditación del conocimiento de idiomas como requisito de solvencia a aquellos respecto a los que se hace un mayor número de traducciones y ello sin perjuicio de prever la subcontratación del resto de idiomas para el caso de ser necesario el empleo de los mismos». Consecuentemente, la solvencia y la proporcionalidad ligada a ella, determina que los requisitos tampoco deben ser excesivos, máxime cuando, como en este caso, sería previsible que la traducción a 44 idiomas se produciría en muy contadas ocasiones, solo en algunos supuestos y el ser tan exigentes y desproporcionados se estaría excluyendo, además, a empresarios que con toda probabilidad estarían en condiciones de cumplir el objeto del contrato.

Algo similar ocurre en una Resolución del TACRC 217/2012, de 03-10-2012, que analiza un supuesto donde los pliegos exigían a las empresas licitadoras que contasen con una plantilla de mil vigilantes en plantilla en el momento de presentación de las ofertas, para cubrir solamente plazas para cincuenta y ocho vigilantes. El Tribunal considera que hay una desproporción y, consecuentemente, una falta de relación entre las exigencias del pliego y el objeto del contrato ${ }^{25}$. Y esta situación ha ocurrido no solamente desde un punto de vista cuantitativo, sino también cualitativo, por exigencia, por ejemplo, de un número de años de experiencia desproporcionado en relación con el concreto objeto del contrato ${ }^{26}$. O bien por pedir que la experiencia se limite exclusivamente a haber desarrollado funciones contenciosas. También encontramos otras Resoluciones que se refieren al supuesto de que la experiencia se exija respecto a entidades locales o municipios de más de 50.000 habitantes, porque se está limitando el principio de

24 Por ejemplo, en la Resolución del TACRC 249/2012, de 07-11-2012, se afirma que los criterios de solvencia «deben ser objetivos y garantizar el cumplimiento de los principios de proporcionalidad y no discriminación (...) lo que debe determinarse en cada caso (...) evitando así que se produzca el efecto de discriminación entre empresas capacitadas para la ejecución del contrato, contrario a los principios de concurrencia e igualdad que deben presidir la contratación administrativa (...) habiéndose pronunciado en numerosas ocasiones la Junta Consultiva de Contratación Administrativa acerca de la posibilidad de exigencia de experiencia a las empresas licitadoras, como criterio para medir su solvencia técnica, cuestión que generalmente ha planteado dudas en aquellos casos en que se ha incluido la experiencia entre los criterios de adjudicación del contrato, posibilidad rechazada por la JCCA, en aplicación de la normativa comunitaria, habiendo declarado en múltiples ocasiones que la experiencia puede ser utilizada como criterio de solvencia técnica, pero no de adjudicación».

25 Otro supuesto similar se planteaba en la Resolución 548/2014, de 18 de julio, del TACRC que anulaba la licitación para la contratación de un vehículo de reconocimiento destinado a la UME (Unidad Militar de Emergencias), puesto que exigía la necesidad de contar el licitador con un licenciado en biología, siendo el caso que dicha especialidad resultaba ajena al objeto del contrato. O la Resolución 288/2011, de 21 de septiembre, que anula una licitación de TRAGSA, que exigía como criterio de solvencia contar con una plantilla de más de 11 vigilantes cuando solo eran necesarios 6 para el desarrollo del contrato.

26 Por ejemplo, Resolución del TARC de Castilla y León 79/2016, de 16-11-2016. En la misma el Tribunal entiende, por ejemplo, que es desproporcionado que la única forma que se permita para acreditar la experiencia profesional en el ámbito administrativo es haber estado colegiado como abogado ejerciente durante un tiempo de 10 años, siendo así que también pueden tener amplios conocimientos jurídico-administrativos quienes los hayan adquirido como funcionarios públicos o cualquier otra profesión jurídica, aunque no necesite colegiación. Sí se entiende, sin embargo, que es proporcional, que la exigencia de que la experiencia en el asesoramiento consultivo y contencioso a un Ayuntamiento solo pueda acreditarse mediante servicios prestados únicamente a entes de la Administración Local, por las singularidades que presenta en su régimen de contratación, personal, sistema tributario, disciplina y régimen urbanístico, recursos, etc., y que «la alegación de los recurrentes de que consideran indiferente que la experiencia para acreditar la solvencia técnica o la profesional se haya prestado en el sector público o en el privado no es atendible por dicha circunstancia». 
libre concurrencia en la contratación pública, siempre y cuando no se ofrezcan alternativas que permitan acceder a otros licitadores con experiencia suficiente aunque sea en municipios de población inferior: «... debiendo señalarse, por otro lado, que si se cumple este requisito es porque, en alguna licitación, por vez primera, no se le exigió, lo cual encierra, en cierto modo, sobre una incongruencia, una discriminación... (y que) el órgano de contratación debe introducir fórmulas que, a la par que satisfagan la acreditación de la solvencia, permitan abrir la contratación a otros licitadores, sin merma de la exigencia de solvencia técnica o profesional» ${ }^{27}$.

Otro supuesto práctico similar lo fue la licitación de un contrato de servicios de asesoramiento jurídico y tributario para una Autoridad Portuaria, exigiéndose a los licitadores haber realizado durante los últimos cinco años prestaciones de servicio de igual o similar naturaleza a los que constituyen el objeto de este contrato, debiendo acreditar, la realización de al menos 3 servicios de asesoramiento tributario a Autoridades portuarias, incluyendo asesoramiento en el Impuesto sobre Sociedades ${ }^{28}$. Limitaciones que merman y mucho la capacidad de concurrencia a posibles licitadores.

Cierto es, también, que no hay una fórmula matemática que permita medir la proporcionalidad, como señala la Resolución TACRC 206/2014, de 07-03-2014, por lo que habrá que acudir también a las circunstancias del caso y tener en cuenta todos los posibles factores que concurran.

\section{LA INTEGRACIÓN DE LA SOLVENCIA CON MEDIOS EXTERNOS}

El arts. 75 LCSP regula, también, la integración de la solvencia acudiendo a medios externos, permitiendo que el empresario pueda basarse en la solvencia y medios de otras entidades ${ }^{29}$, independientemente de la naturaleza jurídica de los vínculos que tenga con ellas, lo que permitiría el acceso de las PYMES a la contratación pública, que de otra forma no podrían llegar a muchas licitaciones, porque se les permite a las empresas que concurran a través de Uniones Temporales de Empresas (art. 69 LCSP) o en solitario, siempre que demuestren que durante toda la ejecución del contrato van a contar con dichos medios y que esas otras empresas no están incursas en prohibiciones para contratar ${ }^{30}$. Incluso los empresarios incluidos en las UTES podrían acudir a capacidades de empresas ajenas a la unión temporal. Respecto a estas Uniones Temporales, señalar que no procede exigir que los fines, el objeto y el ámbito de actividad de cada una de las empresas coincida con todas las prestaciones objeto del contrato, sino que habrá que estar a la parte del contrato que se desea acreditar a través de estos medios.

Parece que la nueva Ley quiere facilitar el terreno a este tipo de empresas, en un campo tradicionalmente dominado por las grandes empresas y donde se reparte una tarta de muchos millones de euros. Entre otras cuestiones, se les reduce también la carga administrativa, facilitado entre otras cosas por el Documento Europeo Único de Contratación, en el que aparecerán los datos relativos a la trayectoria profesional, solvencia y capacitación que posean, avalados por certificados e informes de trabajos anteriores. Y

27 Como ya habíamos tenido ocasión de señalar anteriormente en relación con la Resolución del TACRC 207/2014, de 14 de marzo.

28 La Resolución 41/2014, de 19 de mayo del TARC de Castilla y León entiende que no cabe establecer como criterio de solvencia la experiencia en contratos anteriores para la misma entidad. También se ha cuestionado la exigencia de acreditar la experiencia con un ente o tipo de Administración concreta, como en el acuerdo de TACP de Aragón 28/2014, de 12 de mayo, referido a un procedimiento en el que solo se admitían los que hubieran sido realizados para entidades locales. O la Resolución del TACP de Madrid 113/2017, de 5 de abril, que entiende es desproporcionado exigir un número de 5 certificados de trabajos similares sin identificar el importe anual, así como solicitar experiencia en trabajos similares solo en Ayuntamientos. La Resolución del TACRC 1009/2016, de 2 de diciembre también consideró limitativo exigir que todos los contratos acreditativos de la experiencia hubieran tenido que realizarse para entidades del sector público. O la Resolución del TACP de la Comunidad de Madrid 113/2007, de 5 de abril que considera desproporcionado exigir un número de cinco certificados de trabajos similares sin identificar el importe anual que deben alcanzar.

29 Para acreditar la solvencia técnica o profesional puede utilizarse la experiencia previa de sujetos que colaboran con ella (empleados, integrantes de UTE, profesionales que se comprometen a colaborar con la empresa licitadora si obtiene la ejecución). Se puede consultar, BUDRÍA ESCUDERO, A. (2013) "La acreditación de la solvencia por medios externos", en Revista de estudios locales. Cunal, núm. 161 (extra), pág. 235 y ss.; CEA AYALA, A. (2016) "Requisitos de solvencia del empresario", en Revista de Contratación Administrativa Práctica, núm. 146, pág. 20 y ss.

30 Por referencia a esos medios externos la empresa podrá acreditar la disponibilidad tanto del personal técnico cualificado como de medios materiales, maquinaria, instalaciones, equipos, como afirma el informe de la JCCA del Estado 45/2002, de 28-02-2003, o de la JCCA de Castilla La Mancha 6/2012, de 21-12-2012, y ello independientemente de la relación o contrato que la empresa licitadora tenga con las que van a prestar dichos medios, como afirma el TARC de la Junta de Andalucía 103/2013, de 02-08-2013. 
fundamental, con otra cuestión a la que luego haremos también alusión, la reducción de años de experiencia exigidos, que pasan de 10 a 5 en los contratos de obras y de 5 a 3 en los de prestación de servicios.

Las empresas únicamente podrán recurrir a las capacidades de esas otras entidades si las mismas van a ejecutar las obras o prestar los servicios para los cuales son necesarias dichas capacidades y deberán demostrarlo al poder adjudicador mediante la presentación de un compromiso por escrito de dichas entidades. Compromiso que no se exigirá a todos los licitadores, sino solo a aquel que hubiera presentado la mejor oferta, por lo que el momento de la justificación será el momento de la clasificación de ofertas y la adjudicación del contrato, conforme al art. 150.2 LCSP, en relación con el art. 140.1.c), ambos de la LCSP. Aunque no será sólo el compromiso lo que hay que justificar sino todos los requisitos comprendidos en las letras a) a c) del citado art. $140.1^{31}$ (requisitos de capacidad, solvencia, no estar incursos en prohibiciones para contratar), salvo que el empresario esté inscrito en el Registro Oficial de Licitadores y Empresas Clasificadas del Sector Público, o figure en una base de datos nacional de un Estado miembro de la Unión Europea, como en un expediente virtual de la empresa, en un sistema de almacenamiento electrónico de documentos o en un sistema de precalificación, y estos sean accesibles de modo gratuito para los citados órganos, en cuyo caso, no estará obligado a presentar los documentos justificativos u otra prueba documental de los datos inscritos en los referidos lugares.

Como se afirma en GARCÍA SANTOS, J. y JURADO JIMÉNEZ, J. C. ${ }^{32}$, «la integración de la solvencia con medios externos ... ha sido fruto fundamentalmente de una construcción jurisprudencial por parte del TJUE, cuyos criterios han ido positivizándose, primero en las correspondientes Directivas y después en nuestra ley nacional».

En estos supuestos, el poder adjudicador podrá exigir formas de responsabilidad conjunta, incluso solidaria, de acuerdo con el art. 75.3 LCSP. Se presupone que si la responsabilidad es conjunta o mancomunada, previamente el contratista y las empresas que aportan los medios externos habrán tenido que establecer a través de acuerdos privados y ajenos a las entidades del sector público con quien se contrata, cuál será la proporción de responsabilidad que corresponde a cada uno de los empresarios. Supone una novedad con respecto al TRLCSP puesto que este texto solo exigía al subcontratista que pusiera sus medios al servicio del contratista principal, un compromiso de puesta a disposición, pero no una responsabilidad compartida.

Además, de acuerdo con el apartado $4 .^{\circ}$ de este mismo art. 75 LCSP, «en el caso de los contratos de obras, los contratos de servicios, o los servicios o trabajos de colocación o instalación en el contexto de un contrato de suministro, los poderes adjudicadores podrán exigir que determinadas partes o trabajos, en atención a su especial naturaleza, sean ejecutadas directamente por el propio licitador o, en el caso de una oferta presentada por una unión de empresarios, por un participante en la misma, siempre que así se haya previsto en el correspondiente pliego con indicación de los trabajos a los que se refiera». Indicación concreta, pero no porcentual ${ }^{33}$ como ha afirmado el propio TJUE, aunque parecería lógico exigir que un mínimo de los trabajos fuera realizado directamente por el licitador.

Por su parte, el art. 76 LCSP, en su párrafo tercero, incorpora como novedad, aunque esté relacionado más bien con la acreditación de la solvencia por medios externos, que «la adscripción de los medios personales o materiales como requisitos de solvencia adicionales a la clasificación del contratista deberá ser razonable, justificada y proporcional a la entidad y características del contrato, de forma que no limite la participación de las empresas en la licitación». Volvemos a encontrar referencias, nuevamente a la proporcionalidad, la razonabilidad, como principios generales que afectan a la contratación administrativa.

31 EI TACRC distingue entre acreditar la solvencia, que debería hacerse en la oferta y la acreditación de la disponibilidad efectiva de medios, que debería hacerse cuando ya se ha elegido la oferta económicamente más ventajosa y justo antes de la adjudicación. Resoluciones 274/2014, de 28-03-2014; 409/2014, de 23-05-2014; 837/2016, de 21-10-2016; 870/2016, de 28-10-2016.

32 (2018), op. cit., pág. 1.078 y ss., que citan una abundante jurisprudencia del TJUE: STJUE de 02-12-1999, Holst Italia, (Asunto C-176/98); STJUE de 10-10-2013, Swm Costruzioni 2 y Mannocchi Luigino, (Asunto C-94/12); STJUE de 07-04-2016, Partnert Apelski Dariusz, (Asunto C-324/14); SSTJUE de 14-01-2016, Ostas celtnieks, SIA, (Asunto C-324/14) y la de 02-06-2016, Pippo Pizzo, (Asunto C-27/15), sentencias estas dos últimas que admiten un sistema amplio de medios acreditativos para justificar la disponibilidad de los medios externos. También STJUE de 14-09-2017, Casertana Construzioni, Srl, (Asunto C-223/16) en la que se exigen dos importantes condicionantes: uno, que para recurrir a dichos medios externos es necesario que esas otras empresas vayan a ejecutar las obras o prestar los servicios para los que se acreditan sus medios; dos, que si no cumplieran los criterios de selección o existe algún motivo de exclusión obligatoria, el poder adjudicador podría exigir su sustitución.

33 En la STJUE de 14 de julio de 2016, asunto C-406/14, se señala, interpretando la anterior Directiva 2004/18/CE de 31 de marzo de 2004 , sobre coordinación de los procedimientos de adjudicación de los contratos públicos de obras, de suministro y de servicios, que un poder adjudicador «no puede exigir mediante una cláusula del pliego de condiciones de un contrato público de obras, que el futuro adjudicatario de dicho contrato ejecute con sus propios recursos un determinado porcentaje de las obras objeto del mismo». 


\section{LOS MEDIOS PARA ACREDITAR LA SOLVENCIA TÉCNICA}

Se regulan en la nueva LCSP en los artículos 86 y ss. en función de los distintos tipos de contratos. Hacen referencia a la experiencia, los medios humanos y materiales, la subcontratación, así como medidas de gestión medioambiental. Se producen en estas cuestiones algunas novedades con respecto al TRLCSP.

El art. 86 LCSP (anterior art. 74 TRLCSP) sigue diferenciando entre contratos sometidos a regulación armonizada y los que no, respecto a la aportación de los documentos necesarios para acreditar los requisitos de solvencia, que serán los que determine el órgano de contratación de entre los previstos en los artículos 87 a 91 de la Ley para el caso de los contratos sometidos a regulación armonizada y, para los que no lo están, el órgano de contratación podrá admitir de forma justificada otros medios de prueba. Pero, esa opción, en la regulación anterior se daba respecto a entes, organismos y entidades del sector público que no tengan la condición de Administraciones Públicas y ahora la nueva Ley no distingue por clase de sujetos del sector público.

Otra diferencia es que mientras que para acreditar la solvencia económica o financiera y técnica o profesional se deja a criterio del órgano de contratación ${ }^{34}$ la determinación de los medios, cuando es para la clasificación de empresas, los documentos serán los que vengan reglamentariamente establecidos. Respecto a la clasificación, si con la regulación anterior era para la celebración de contratos del mismo tipo, con la nueva LCSP se añade además que tienen que ser del mismo importe.

Se añade, también, que cuando se trata de contratos de concesión de obras y concesiones de servicios en los que puedan identificarse sucesivas fases de ejecución para las que se requieran medios y capacidades distintas, los pliegos podrán diferenciar requisitos de solvencia distintos y los licitadores podrán acreditarlos con anterioridad al inicio de la ejecución de cada una de las fases. Y que, si no acreditaran su solvencia antes de la ejecución de la correspondiente fase, se resolverá el contrato por causas imputables al empresario.

Si nos centramos ya en la solvencia técnica y los distintos aspectos que pueden hacer referencia a la experiencia, son varias también las novedades de la Ley por referencia al anterior TRLCSP.

Respecto a la solvencia técnica en los contratos de obras, el art. 88 LCSP rebaja de diez a cinco últimos años la relación de obras ejecutadas, aunque a continuación se especifica que cuando sea necesario para garantizar un nivel adecuado de competencia, los poderes adjudicadores podrán indicar que se tendrán en cuenta las pruebas de las obras pertinentes efectuadas más de cinco años antes. Estas obras tendrán que venir avaladas por certificados de buena ejecución, los cuales indicarán el importe, las fechas y el lugar de ejecución de las obras y se precisará si se realizaron según las reglas por las que se rige la profesión y se llevaron normalmente a buen término, con la previsión que ya hemos indicado de que puede irse más allá de los cinco años.

Se admite, para acreditar la experiencia, las obras ejecutadas por una sociedad extranjera filial del contratista, con la misma consideración que las que han sido ejecutadas directamente por él, siempre que este ostente directa o indirectamente el control de aquella en los términos del art. $42 \mathrm{CCo}$. Si no se cumple esta condición, sólo se reconocerá como experiencia atribuible al contratista la obra ejecutada por la sociedad participada en la proporción de la participación de aquel en el capital social de esta.

${ }^{34}$ Eso sí, cumpliendo una serie de requisitos recogidos por la JCCA del Estado (Informes 51/2005, de 19-12-2005; 36/2007, de 0507-2017), y por el TACRC (Resoluciones 16/2012, de 13-01-2012; 212/2013, de 05-06-2013; 791/2014, de 24-11-2014), como que figuren en el pliego del contrato y en el anuncio de licitación, la determinación, la relación con el objeto y el importe de los contratos, la relación con los exigidos por la Ley en función del tipo de contrato y que no produzcan discriminación (aunque no será tal que alguno de los candidatos no pueda alcanzar el nivel de solvencia exigido). Además, «no basta, pues, con que el anuncio fije el requisito mínimo y se remita a la ley respecto al medio de acreditación, sino que es necesario que ambos se expresen en el anuncio de forma breve y escueta, pero, a la vez, suficiente para que cualquier licitador pueda conocer estos aspectos sin tener que acudir a otra fuente de información. La indicación nunca puede satisfacerse por remisión, sino por una breve descripción o reseña que, obviamente, no tiene que alcanzar el nivel de detalle y explicación del pliego» (Resolución TARCJA 151/2016, de 01-07-2016). Los medios exigidos para acreditar la solvencia no deben ser irracionales o inadecuados (Resolución TACRC 32/2011, de 16-02-2011; 271/2012, de 30-11-2012; de 01-04-2016, JUR 2016/246393, en relación con un contrato de servicios de redacción del proyecto de remodelación del edificio del Banco de España y la dirección facultativa y coordinación de seguridad y salud de las obras de reorganización de los espacios bancarios, afirma que «la concreción de los requisitos mínimos de solvencia económica y financiera y de solvencia técnica o profesional exigidos para un contrato, así como de los medios admitidos para su acreditación, se determinará por el órgano de contratación y se indicará en el anuncio de licitación o en la invitación a participar en el procedimiento y se detallará en los pliegos, en los que se concretarán las magnitudes, parámetros o ratios y los umbrales o rangos de valores que determinarán la admisión o exclusión de los licitadores o candidatos», sin que sea factible, que el propio Pliego de Condiciones deje plena discrecionalidad al órgano de contratación, «lo cual es contrario al principio de transparencia que, como garantía de la libre concurrencia, preside la contratación pública», razón por la cual anula las previsiones del Pliego de Condiciones en tal sentido). O la Resolución TACJCL 30/2016, de 05-05-2016, que entiende que la concreción de la solvencia no puede ser desproporcionada respecto a la complejidad técnica del contrato, con su dimensión económica o vinculada a la misma, porque en tal caso, sería un elemento de restricción indebida de la competencia. 
Y que en los contratos cuyo valor estimado sea inferior a $500.000 €$, cuando el contratista sea una empresa de nueva creación, entendiendo por tal aquella que tenga una antigüedad inferior a cinco años, su solvencia técnica se acreditará por uno o varios de los medios a que se refieren las letras b) a f) del mismo artículo, sin que en ningún caso sea aplicable lo establecido en la letra a), relativo a la ejecución de un determinado número de obras. Aunque lo cierto es que en la letra a) se refiere al número de años, pero no de obras, habla de relación de obras ejecutadas, no realmente de número de ellas. Hay que tener en cuenta también que estos requisitos se refieren a contratos de obras de cuantía inferior a $500.000 €$, ya que si es superior la empresa debería estar clasificada. Novedad importante, entiendo, puesto que elimina el requisito de la experiencia por el número de obras ejecutadas en relación con las empresas de nueva creación, lo que favorecerá, evidentemente, su entrada en el mercado contractual con los entes del sector público. La contrapartida a esta ventaja, que se trata de contratos de escasa cuantía.

Aparte de la relación de obras ejecutadas, otros medios harán referencia a los siguientes aspectos: la relación del personal técnico u organismos técnicos, estén o no integrados en la empresa, de los que la misma disponga para la ejecución de las obras, acompañada de los documentos acreditativos correspondientes; los títulos académicos y profesionales del empresario, directivos, así como responsable o responsables de las obras y de los técnicos encargados directamente de la misma, eso sí, siempre que no se evalúen como criterio de adjudicación; las medidas de gestión medioambiental, aunque dependerá del contrato puesto que la LCSP hace referencia a aquellos casos que sean adecuados; la declaración sobre la plantilla media anual y el número de directivos durante los tres últimos años, acompañada de la documentación justificativa correspondiente cuando le sea requerido; la declaración sobre la maquinaria, material y equipo técnico del que va a disponer para la ejecución de las obras, acompañado de la misma forma por la documentación acreditativa pertinente.

Estos medios se especificarán en el anuncio de licitación o invitación a participar en el procedimiento y en los pliegos, con los valores mínimos exigidos. Respecto a la concreción de esos requisitos mínimos, el art. 92 LCSP determina que tendrán que concretarse las magnitudes, los parámetros o ratios y los umbrales o rangos de valores que determinarán la admisión o exclusión de los licitadores o candidatos. No obstante, y cuando no sea exigida la clasificación, la acreditación de la solvencia técnica se efectuará mediante la relación de obras ejecutadas en los últimos cinco años, que sean del mismo grupo o subgrupo de clasificación que el correspondiente al contrato, o del grupo o subgrupo más relevante para el contrato si este incluye trabajos correspondientes a distintos subgrupos, cuyo importe total acumulado en el año de mayor ejecución sea igual o superior al $70 \%$ de la anualidad media del contrato.

Para aquellos supuestos en que sí que se acredite la solvencia a través de la clasificación del empresario en un determinado grupo o subgrupo, se tendrá por prueba bastante la misma para aquellos contratos cuyo objeto esté incluido o se corresponda con el ámbito de actividades o trabajos de dicho grupo o subgrupo, y cuyo importe anual medio sea igual o inferior al correspondiente a su categoría de clasificación en el grupo o subgrupo. A estos efectos, en el anuncio de licitación o en la invitación a participar en el procedimiento y en los pliegos se deberá indicar el código o códigos CPV correspondientes al objeto del contrato, los que determinarán el grupo o subgrupo de clasificación en que se considera incluido el contrato.

Respecto a la solvencia técnica en los contratos de suministro, el art. 89 LCSP rebaja, de igual forma que anteriormente habíamos comentado, de cinco a tres últimos años la relación de suministros realizados, aunque a continuación se especifica que cuando sea necesario para garantizar un nivel adecuado de competencia, los poderes adjudicadores podrán indicar que se tendrán en cuenta las pruebas de los suministros pertinentes efectuados más de tres años antes. Y que en los contratos no sujetos a regulación armonizada, cuando el contratista sea una empresa de nueva creación, entendiendo por tal aquella que tenga una antigüedad inferior a cinco años, su solvencia técnica se acreditará por uno o varios de los medios a que se refieren las letras b) a g), es decir, el resto de requisitos a los que haremos alusión, sin que en ningún caso sea aplicable lo establecido en la letra a), a la que ahora hacemos alusión, relativo a la ejecución de un determinado número de suministros ${ }^{35}$. Aunque lo cierto es que en la letra a) se refiere al número de años, pero no de suministros, habla de relación de los principales suministros realizados, sin especificar o exigir un número concreto.

35 Volvemos a encontrar nuevamente la medida a la que ya hemos hecho alusión y que deriva de la Directiva 2014/24 para favorecer el acceso a las PYMES de nueva creación. Véase GIMENO FELIÚ, J. M. ${ }^{a}$ (2012) "La necesidad de un Código de Contratos Públicos en España. La contratación pública y las PYMES como estrategia de reactivación económica”, en libro colectivo Observatorio de los Contratos Públicos 2011, Civitas, Cizur Menor, pág. 25 y ss. 
Lo que sí que deja claro la LCSP es cuándo se entiende que un suministro es de igual o similar naturaleza al que constituye el objeto del contrato: en estos casos, el pliego de cláusulas administrativas particulares podrá acudir además de al CPV, a otros sistemas de clasificación de actividades o productos como el Código normalizado de productos y servicios de las Naciones Unidas (UNSPSC), a la Clasificación Central de Productos (CPC) o a la Clasificación Nacional de Actividades Económicas (CNAE), que en todo caso deberá garantizar la competencia efectiva para la adjudicación del contrato. En defecto de previsión en el pliego se atenderá a los tres primeros dígitos de los respectivos códigos de la CPV. La Junta Consultiva de Contratación Pública del Sector Público podrá efectuar recomendaciones para indicar qué Códigos de las respectivas clasificaciones se ajustan con mayor precisión a las prestaciones más habituales en la contratación pública.

El resto de los requisitos son similares a los que hemos hecho referencia anteriormente al referirnos al contrato de obras, aunque adaptados al objeto contractual de esta modalidad. Respecto al personal técnico o unidades técnicas, las exigencias son las mismas ${ }^{36}$, aunque con expresa mención de los encargados del control de calidad. Habrá que describir las instalaciones técnicas, las medidas empleadas para garantizar la calidad, así como los medios de estudio e investigación de la empresa. El control público sobre los productos a suministrar cuando estos sean complejos o deban responder a un fin particular ${ }^{37}$. Se podrán exigir muestras, descripciones y fotografías de los productos a suministrar, así como certificados expedidos por los institutos o servicios oficiales encargados del control de calidad, con competencia reconocida. Se añade un requisito adicional en la letra g) relativo a la indicación de los sistemas de gestión de la cadena de suministro, incluidos los que garanticen el cumplimiento de las Convenciones fundamentales de la Organización Internacional del Trabajo, y de seguimiento que el empresario podrá aplicar al ejecutar el contrato.

La concreción de cuáles de estos medios van a ser exigidos para acreditar la solvencia se realizará en el anuncio de licitación o invitación a participar en el procedimiento y en los pliegos del contrato y, en su defecto, la acreditación se efectuará mediante la relación de los principales suministros efectuados en los tres últimos años, de igual o similar naturaleza, con un importe anual acumulado en el año de mayor ejecución que sea igual o superior al $70 \%$ de la anualidad media del contrato.

En relación con la solvencia técnica en los contratos de servicios, el art. 90 LCSP rebaja nuevamente de cinco a tres últimos años la relación de suministros realizados, pero se exige que sean de igual o similar naturaleza que los que constituyen el objeto del contrato ${ }^{38}$ y a continuación se especifica que cuando sea necesario para garantizar un nivel adecuado de competencia, los poderes adjudicadores podrán indicar que se tendrán en cuenta las pruebas de los servicios pertinentes efectuados más de tres años antes. Y que, en los contratos no sujetos a regulación armonizada, cuando el contratista sea una empresa de nueva creación, entendiendo por tal aquella que tenga una antigüedad inferior a cinco años, su solvencia técnica se acreditará por uno o varios de los medios a que se refieren las letras b) a i) que se referencian en el mismo artículo, sin que en ningún caso sea aplicable lo establecido en la letra a), relativo a la ejecución de un determinado número de servicios. Aunque, y volvemos a repetirnos, lo cierto es que en la letra a) se refiere al número de años, pero no de servicios, ya que habla de relación de los principales servicios o trabajos realizados.

Además, se especifica que para determinar que un trabajo o servicio es de igual o similar naturaleza al que constituye el objeto del contrato, el pliego de cláusulas administrativas particulares podrá acudir ade-

36 Resolución del TACP de la Comunidad de Madrid 925/2016, de 11 de noviembre, donde se considera que la limitación de cualificación a arquitectos e ingenieros de caminos, canales y puentes, con exclusión de los ingenieros industriales, infringe el principio de concurrencia. Respecto a este personal también se han analizado por nuestros Tribunales de Contratos la cuestión relativa al número de años de experiencia: en la resolución del TACRC 55/2016, de 17 de marzo, se consideró ajustado a derecho el criterio de la solvencia por estar vinculado con el objeto del contrato y respetar el principio de proporcionalidad. En el supuesto planteado se había exigido un determinado número de años de experiencia del equipo de personal adscrito a la ejecución del contrato, concretamente en la realización de campañas formativas/informativas en las que hayan intervenido personas con reconocida repercusión mediática o social.

${ }^{37}$ En la Resolución del TACRC 109/2014, de 14-02-2014, se planteaba un supuesto en que se exigía en el pliego de condiciones que los licitadores que habían contratado previamente con el Organismo Autónomo de referencia aportaran un certificado de buena ejecución expedido concretamente por este, lo que suponía, a juicio del Tribunal, una restricción a la facultad que confiere a los licitadores el anterior art. 89.1 a) LCSP para escoger, de entre sus contratos anteriores los que estimaran pertinentes o adecuados para acreditar la solvencia y que, de esta forma, se estaría instaurando «una suerte de prohibición para contratar cuya aplicación queda al albur de la propia Administración Pública que licita el contrato y que operaría al margen de los casos y del procedimiento regulado en los artículos 60 y 61 TRLCSP». En la Resolución TARC de la Junta de Andalucía de 01-04-2016, 2016/250953, se establece también que, para evitar obstáculos injustificados a la libre concurrencia, la referencia a los certificados debe acompañarse de la mención «o equivalente».

38 «La exigencia de una experiencia mínima como criterio de selección (que no de adjudicación) se admite legalmente aunque a priori no puedan cumplirla todos los potenciales licitadores, ya que no se considerará discriminatorio siempre que existan fundados motivos y razones para ello, de lo cual deberá dejarse constancia en el expediente de contratación» como afirman GARCíA SANTOS, J. y JURADO JIMÉNEZ, J. C. (2018), op. cit., pág. 1.103. 
más de al CPV, a otros sistemas de clasificación de actividades o productos como el Código normalizado de productos y servicios de las Naciones Unidas (UNSPSC), a la Clasificación Central de Productos (CPC) o a la Clasificación Nacional de Actividades Económicas (CNAE), que en todo caso deberá garantizar la competencia efectiva para la adjudicación del contrato. En defecto de previsión en el pliego se atenderá a los tres primeros dígitos de los respectivos códigos de la CPV. La Junta Consultiva de Contratación Pública del Estado podrá efectuar recomendaciones para indicar qué Códigos de las respectivas clasificaciones se ajustan con mayor precisión a las prestaciones más habituales en la contratación pública (idéntica previsión que para los contratos de suministros).

Una diferencia con respecto a la regulación anterior es que la acreditación de los servicios ahora se hará cuando le sea requerido por los servicios dependientes del órgano de contratación. De la misma forma que la documentación correspondiente a la declaración sobre la plantilla media anual de la empresa y el número de directivos durante los tres últimos años, o sobre la maquinaria, material y equipo técnico del que dispondrá para la ejecución de los trabajos o prestaciones. El resto de los requisitos que, en su caso, podrán ser exigidos para acreditar la solvencia son similares a los recogidos con respecto a los contratos anteriores.

Serán nuevamente los anuncios de licitación, la invitación a participar en los procedimientos y los pliegos del contrato los que especifiquen los medios de acreditación de la solvencia, aunque en su defecto, la acreditación «se efectuará mediante la relación de los principales servicios efectuados en los tres últimos años, de igual o similar naturaleza que los que constituyen el objeto del contrato, cuyo importe anual acumulado en el año de mayor ejecución sea igual o superior al 70 por ciento de la anualidad media del contrato» ${ }^{39}$.

Por otra parte, dentro de la tónica general de clausulado medioambiental y social de la nueva LCSP, se hace referencia expresa a la indicación de las medidas de gestión medioambiental que el empresario podrá aplicar al ejecutar el contrato y se añade un nuevo apartado con específicos requisitos de solvencia técnica o profesional, cuando el objeto contractual requiriese aptitudes específicas en materia social, de prestación de servicios de proximidad u otras análogas, y es la concreta experiencia ${ }^{40}$, conocimientos y medios en las referidas materias, lo que deberá acreditarse por los medios que establece el apartado 1 de este artículo.

39 HUERGO LORA, A. (2017), op. cit., pág. 2 maneja el proyecto de la nueva LCSP, que resulta un poco diferente en su redacción y nos dice que en este último párrafo que comentamos que «no es un criterio imperativo para los pliegos, sino supletorio». Lo que se deduce, a mi entender, de la redacción del art. 90 LCSP es que los pliegos pueden contener otros medios de acreditación de la solvencia y que sólo en defecto de regulación expresa en los mismos jugará la acreditación especificada expresamente en la Ley. En relación también con la experiencia, la STSJ de Aragón 89/2013, de 15 de junio de 2016, anuló un acuerdo del TACP de Aragón 9/2013, de 18 de febrero, considerando que no es admisible establecer como medio de acreditación de la solvencia técnica sólo la acreditación de la experiencia porque de esta forma sería imposible que accedieran entidades empresariales que no tuvieran experiencia previa de gestión, siendo así que la legislación de contratos establece diferentes formas de acreditar la solvencia técnica además de la experiencia. Y la Resolución 333/2016, de 29 de abril, del TACPM, considera que no se puede exigir como requisito de solvencia técnica y profesional el haber sido abogado colegiado durante los últimos 10 años, así como haber sido adjudicatario de tres contratos anteriores similares al que se licitaba con Ayuntamientos de 20.000 habitantes. El Tribunal entiende en este caso que estas exigencias limitan la concurrencia y son desproporcionadas, y que pueden utilizarse fórmulas alternativas en el ámbito local.

40 Respecto a la experiencia ya hemos tenido ocasión de pronunciarnos, en concreto en el tema de la proximidad. En la Resolución 21/2012, de 16 de octubre de TACRC de Castilla y León se reafirma en la prohibición de «los criterios de solvencia, o de adjudicación, que primen los aspectos relativos a la nacionalidad o regionalidad de la empresa, como ha señalado de modo reiterado la jurisprudencia comunitaria, entre otras, STJUE de 27 de octubre de 2005» (asunto C-185/03: en ella, la Comisión de las Comunidades Europeas solicita al Tribunal de Justicia que declare que el Reino de España ha incumplido las obligaciones que le incumben con arreglo a los artículos $43 \mathrm{CE}$ y $49 \mathrm{CE}$, al incluir, en los pliegos de condiciones de diversas licitaciones convocadas por el Instituto Nacional de la Salud -en lo sucesivo, «Insalud»-para la prestación de servicios de terapias respiratorias domiciliarias, unos criterios de admisión, de valoración y de desempate entre dos licitadores con la misma puntuación que hacen referencia al hecho de disponer, en el momento de la presentación de las ofertas, de determinadas instalaciones en territorio español o en un radio de $1.000 \mathrm{~km}$ de la provincia en que se haya de prestar el servicio, así como al hecho de disponer previamente de oficinas de atención al público en determinadas localidades. Precisamente el tema del domicilio social o arraigo territorial de la empresa entienden nuestros organismos que no pueden estar relacionados con el requisito de la experiencia: informe JCC del Estado 36/07, de 05-07-2007, que se refiere a la exigencia de que la experiencia se acredite mediante el desarrollo de trabajos en una región o estado determinados; o la 9/2009, de 31 de marzo; o la Resolución del TACRC 275/2017, de 12-05-2017, en aplicación de la Directiva de contratación 2014/24; 359/2017, de 21 de abril; 426/2017, de 12 de mayo; 328/2018, de 6 de abril; 462/2018, de 11 de mayo.

En otra STJUE de 22-10-2015, asunto C-552/13, se examinaba un contrato de servicios de salud sometido a la Directiva 2004/18, licitado por el Departamento de Sanidad del Gobierno Vasco, en la que se exigía que la ejecución de las prestaciones se efectuara exclusivamente en el término municipal de Bilbao, y en este caso el Tribunal estimó que la proximidad no garantizaba un acceso igual y no discriminatorio de todos los posibles licitadores y que por lo tanto vulneraba el art. 23, apartado 2 de la citada Directiva.

Sin embargo, como afirma MEDINA ARNÁIZ, T. (2017), "El requisito de solvencia en la Ley de Contratos del Sector Público", en Observatorio de los contratos públicos, GIMENO FELIÚ, J. M. ${ }^{a}$ (Director), Thomson Reuters Aranzadi, pág. 204: «en atención al novedoso artículo 90.3 de la LCSP, uno de esos supuestos (se refiere a la modulación de la prohibición absoluta del arraigo territorial como requisito de solvencia técnica) podría darse cuando se trate de adjudicar contratos de prestación de servicios sociales personalísimos, 
La Directiva 2014/24 regula los criterios de selección en su artículo 58 y, cuando se refiere a la capacidad técnica y profesional, en su apartado $4 .^{\circ}$ permite que los poderes adjudicadores impongan requisitos para asegurar que los operadores económicos posean la experiencia y los recursos humanos y técnicos necesarios ${ }^{41}$ para ejecutar el contrato con un nivel adecuado de calidad. Exigiendo, incluso, la demostración de la experiencia mediante referencias adecuadas de contratos ejecutados en el pasado, pero dejando un amplio margen a los poderes adjudicadores para concretar cómo valorar dicha experiencia.

Por otro lado, en los arts. 89.1.a) y 90.1.a) LCSP, referidos a los contratos de suministros y servicios, respectivamente, se utiliza la expresión de igual o similar naturaleza para justificar la experiencia previa del operador económico. No dependerá exclusivamente de la apreciación subjetiva del órgano de contratación, sino que se delimita por los códigos CPV ${ }^{42}$. Como afirma el TACRC, en su Resolución 207/2018, de 2 de marzo (y en la 442/2018, de 27 de abril, «para apreciar la similitud ente el objeto de los servicios o contratos realizados y los que son objeto del contrato, toda vez que se trata de acreditar la solvencia técnica de la empresa, ha de atenderse a una valoración de las condiciones técnicas exigidas a aquellos trabajos comparándolos con las exigidas en el contrato objeto de licitación, atendiendo para ello a los pliegos de prescripciones técnicas toda vez que a ellos está reservado especificar las características técnicas que haya de reunir la realización de las prestaciones del contrato» ${ }^{43}$.

Respecto al resto de los contratos, el art. 91 LCSP establece que podrá realizarse por los documentos y medios previstos para los contratos de servicios.

Del resto de los artículos hay pocas modificaciones, aunque relevantes: en cuanto a la concreción de los requisitos y criterios de solvencia, el art. 92 LCSP se remite ahora no al reglamento ${ }^{44}$ para suplir los establecidos en los anuncios de licitación, invitación a participar en el procedimiento y pliegos de condiciones, sino directamente a los establecidos en los artículos 87 a 90 de la Ley para cada tipo de contratos. Con ello se está elevando a rango legal una materia que antes estaba regulada por el reglamento, constituyendo uno de los ejemplos por los cuales se levantan críticas respecto a esta Ley, precisamente la excesiva regulación de cuestiones que tendrían cabida perfectamente en una regulación reglamentaria.

Por otro lado, el art. 93, introduce entre los certificados para acreditar el cumplimiento de las normas de garantía de la calidad ${ }^{45}$, una especificación respecto a la accesibilidad para las personas con discapacidad. $Y$ en lo relativo al medio ambiente, hacer una referencia en primer lugar al art. 1.3 de la Ley que ya reconoce dentro del objeto y finalidad de la Ley los criterios medioambientales y sociales, que deben ser incorporados de manera transversal y preceptiva en toda la contratación pública. Pues bien, para materia medioambiental ${ }^{46}$, este art. 93 no solo admite el sistema comunitario de gestión y auditoría medioambientales (EMAS)

servicios de proximidad u otros análogos entre cuyas características se encuentre, por ejemplo, el arraigo de la persona en el entorno de atención social, y siempre que el objeto del contrato consista en dotar de continuidad en la atención a las personas que ya eran beneficiarias de dicho servicio».

41 Respecto a las categorías profesionales y titulaciones concretas para acreditar la solvencia técnica del operador económico, las resoluciones de los Tribunales administrativos de recursos contractuales han rechazado la necesidad de que se trate de una profesión o titulación determinada, y lo dejan abierto a un nivel de conocimientos técnicos suficientes. Resoluciones TACRC 153/2017, de 10 de febrero; 517/2017, de 8 de junio; 302/2018, de 23 de marzo.

42 Ya se refería a ello el Real Decreto 1098/2001, de 12 de octubre, modificado por RD 773/2015, de 28 de agosto, de desarrollo de la Ley de Contrato de las Administraciones Públicas, aunque se refería a dos códigos (art. 67) y no a tres como hace ahora la LCSP.

43 En el mismo sentido, Acuerdo 38/2018, de 6 de junio del TACP de Navarra. E informe de la JCCA de la Comunidad de Madrid 7/2016, de 22 de diciembre.

44 En el Dictamen del Consejo de Estado 1116/2015, de 10 de marzo de 2016, que informó el anteproyecto de Ley de Contratos del Sector Público, el órgano consultivo llegaba a la conclusión que el texto resultaba prolijo en cuanto a su regulación e, incluso, farragoso en ocasiones. Que resultaba excesivamente reglamentario en numerosas de sus previsiones porque regulaba cuestiones que podrían deferirse sin dificultad a disposiciones de rango inferior, aunque en otros preceptos el texto incurre en demasía a remisiones a normas reglamentarias de manera injustificada, defiriendo a estas determinaciones que deben hacerse en la norma consultada.

45 Nuevamente recordar, que debemos entenderlos como requisitos de capacidad y no como criterios de adjudicación. Resolución TARC Junta de Andalucía 105/2015, de 17-03-2015. Informes JCCA del Estado 73/2014, de 15-03-2014 y 502/2006, de 11-12-2006.

46 Se puede consultar, entre otros, HERNANDO ACEVEDO, R. (2017) "Los retos ambientales de las nuevas directivas. La contratación pública como herramienta", en Nueva contratación pública, Mercado y Medio Ambiente (dir. RAZQUIN LIZARRAGA, M. M. a), Thomson Reuters Aranzadi, primera edición, pág. 77 y ss., en especial, pág. 114-122; RAZQUIN LIZARRAGA, M. M. a (2017), "Mecanismos para la inclusión de cláusulas ambientales en los contratos públicos”, en Nueva contratación pública, mercado y medio ambiente, recoge las Ponencias al Congreso Internacional Nueva Contratación Pública: mercado y medio ambiente 2016, RAZQUIN LIZARRAGA, M. M. ${ }^{a}$ y ALENZA GARCÍA, J. F. (coordinadores), en especial, pág. 163-167, referido a los criterios de selección y capacidad de los contratistas. Anterior en el tiempo, ALONSO GARCÍA, M. ${ }^{\text {a }}$ C. (2015) "Las novedades introducidas por la Directiva 2014/24/UE en la contratación pública verde", en Observatorio de los Contratos Públicos, núm. monográfico especial sobre Las nuevas Directivas de Contratación Pública (Ponencias sectoriales X Congreso Asociación Española Profesores de Derecho Administrativo), Thomson Reuters Aranzadi, primera edición, pág. 279 y ss., que hace alusión al Libro Verde de la Comisión Europea titulado La contratación pública 
como medio de acreditación, sino también otros reconocidos de conformidad con el art. 45 del Reglamento (CE) núm. 1221/2009 de 25 de noviembre de 2009. También se aceptará una descripción de las medidas de gestión medioambiental ejecutadas, siempre que el licitador demuestre que dichas medidas son equivalentes a las exigidas con arreglo al sistema o norma de gestión medioambiental aplicable (art. 94 LCSP). También se exige que se reconozcan otros certificados equivalentes expedidos por organismos establecidos en cualquier Estado miembro de la Unión Europea y que el órgano de contratación o el órgano auxiliar de este puede recabar del empresario aclaraciones sobre los certificados y documentos presentados o bien requerirle para la presentación de otros complementarios ${ }^{47}$. Si se concurriera a través de una UTE cada una de las entidades debe estar en posesión de los mismos, salvo que se refieran a partes de la prestación del contrato a realizar exclusivamente por una de las empresas, no siendo posible suplir la falta con los certificados de otras empresas, aunque sean del mismo grupo.

\section{FORMA DE ACREDITAR LA SOLVENCIA}

En relación con este último apartado que se ha abordado, queda una cuestión por tratar relativa a la forma en que los licitadores acreditan la solvencia y es que la presentación de las ofertas por los distintos licitadores que concurren no exige desde el principio la presentación de toda la documentación acreditativa del cumplimiento de los requisitos exigidos en los artículos anteriores. La Ley 14/2013, de 27 de septiembre, de apoyo a los emprendedores ${ }^{48}$, había introducido una importante simplificación administrativa para acreditar la aptitud para contratar ${ }^{49}$, modificando el TRLCSP e introduciendo la declaración responsable, que favorecía la reducción de aportación de la documentación acreditativa de dicha aptitud en la fase preliminar del procedimiento de selección, llevándola a una momento posterior, cuando el licitador fuera propuesto como adjudicatario. Un paso más lo supuso la creación del denominado Documento Europeo Único de Contratación (DEUC) ${ }^{50}$, que agiliza aún más el procedimiento al tratarse de un modelo normalizado. No obstante cuando la LCSP habla de los medios para acreditar la solvencia establece la posibilidad de que determinada documentación justificativa «se adjuntará o acompañará, cuando le sea requerido por los servicios depen-

en la UE: reflexiones para el futuro (1996), concretado en las Directivas de contratación de 2004, en la Comunicación de la Comisión Europea sobre Contratación pública para un medio ambiente mejor (2008), cuestiones de las que ya se había hecho eco nuestra Ley de Contratos de 2007, así como el Texto Refundido de 2011. Previamente un Acuerdo del Consejo de Ministros de 22 de mayo de 2006 había creado una Comisión Interministerial para la Incorporación de Criterios Ambientales en la Contratación Pública, que elaboró un Plan de Contratación Pública Verde para la Administración General del Estado, aprobado por Orden/Pres 116/2008, de 21 de enero. Vid. también PERNÁS GARCÍA, J. (2012) "El uso estratégico de la contratación pública como apoyo a las políticas ambientales", en Observatorio de Políticas Ambientales 2012, Aranzadi, Navarra, pág. 299 y ss. y, más concretamente, pág. 311-314. También SARASÍBAR IRIARTE, M. (2015) "La contratación pública se viste de verde", en Observatorio de los Contratos Públicos ..., op. cit., pág. 317 y ss. En relación a las cláusulas sociales, ALMODÓVAR IÑESTA, M. (2019), "Las cláusulas sociales en la contratación pública", en Transparencia, innovación y buen gobierno en la contratación pública, FERNÁNDEZ SALMERÓN, M. y MARTíNEZ GUTIÉRREZ, R. (Directores), Tirant Lo Blanch, Valencia, pág. 387 y ss.

47 Ya el Informe de la JCCA del Estado 1/2006, de 14-12-2006, en relación a las buenas prácticas medioambientales a considerar en la contratación de obras públicas, y en aplicación del principio de proporcionalidad entre las exigencias de dichos certificados y el objeto del contrato nos decía que podían utilizarse como criterios de selección una experiencia determinada en aspectos medioambientales o la exigencia de que los contratistas actuasen en el marco de un sistema de gestión medioambiental (por ejemplo, la ISO 14001, o similar). Respecto al principio de proporcionalidad y relación con el objeto del contrato, nuevamente, Resoluciones TARC de la Junta de Andalucía 50/2016, de 10-03-2016; 83/2016, de 21-04-2016. Y que para evitar discriminaciones, esos otros certificados equivalentes deben venir especificados en el pliego, conforme Resoluciones TACRC 125 y 126/2012, de 04-07-2012.

48 La Ley pretendió introducir una serie de reformas favorables al crecimiento y a la reactivación económica, mediante una mayor valoración de la actividad emprendedora, intentando otorgar beneficios a todas las empresas «con independencia de su tamaño y de la etapa del ciclo empresarial que la que se encuentren» (como dice en su Exp. de Motivos, II). Esas son las razones por las que se introducen una serie de medidas para impulsar la contratación pública con los emprendedores, eliminando posibles obstáculos, considerando como tales las situaciones de ventaja que podían tener en los procedimientos de contratación pública determinados contratistas que previamente ya habían contratado con las Administraciones Públicas.

49 La tendencia a la simplificación ya venía siendo exigida tanto por las Resoluciones del TACRC como por los informes de la JCCA del Estado. Ejemplo, Resolución TACRC 278/2012, de 05-12-2012, informes JCCA del Estado 13/92, de 07-05-1992; 1/94, de 03-02-1994; 26/97, de 14-07-1997. Incluso Sentencias del TS de 05-06-1971 (RJ1971, 3120); 27-11-1984 (RJ 1984, 6617); 06-07-2004 (RJ 2004, 5101).

50 Sobre la declaración responsable y el DEUC, se puede consultar MEDINA ARNÁlZ, T. (2016) "El Documento Europeo Único de Contratación. Un paso más para reducir la carga burocrática en la contratación pública", en Observatorio de los contratos públicos 2015, GIMENO FELIÚ, J. M. (dir.), Aranzadi, Cizur Menor, pág. 247 y ss.; del mismo autor (2019), "Avanzando en la reducción de las cargas administrativas vinculadas a la selección del contratista", en Transparencia, innovación y buen gobierno en la contratación pública, op. cit., pág. 101 y ss. 
dientes del órgano de contratación», sin especificar ni concretar el cuándo, lo que obligaría realmente a los licitadores a tener disponible dicha documentación ${ }^{51}$ en cualquier momento por si le pudiera ser requerida. Con carácter general, no obstante, la disponibilidad tiene que darse desde el primer momento, antes incluso de la finalización del plazo para la presentación de las ofertas y subsistir en el momento de perfección del contrato, es decir, el de su formalización (art. 140.4 y 36 LCSP).

Respecto al DEUC, se introduce por el art. 59 de la Directiva 2014/24, de 26 de febrero, sobre contratación pública y es desarrollado por el Reglamento de Ejecución (UE) 2016/7, de la Comisión, de 5 de enero, que estableció el formulario normalizado de Documento y permite acreditar por parte del licitador y referido al momento de presentación de ofertas, los siguientes aspectos: a) la concurrencia o no de los motivos de exclusión del art. 57 de la Directiva; b) el cumplimiento de los criterios de selección del art. 58 de la Directiva, relativos a la habilitación para ejercer la actividad profesional; la solvencia económico-financiera y la capacidad técnica y profesional; c) el cumplimiento de las normas y los criterios del art. 65 de la Directiva (referido a la reducción del número de candidatos cualificados a los que se invita a participar); y d) lo relativo a terceras empresas a cuyos medios se recurra, conforme al art. 63 de la Directiva.

El DEUC supone una declaración formal, en formato electrónico, que realiza el operador económico, en el que se indica que no es de aplicación motivo alguno de exclusión y/o que cumple los criterios de selección pertinentes, y facilitará la información requerida por el poder adjudicador. Indicará, además, la autoridad pública o el tercero encargado de establecer los documentos justificativos e incluirá una declaración formal en el sentido de que el operador económico podrá, previa petición y sin demora, facilitar dichos documentos justificativos.

\section{UN SUPUESTO ESPECIAL: LA CONTRATACIÓN DE SERVICIOS JURÍDICOS}

Ya hemos visto anteriormente cómo la LCSP incorpora algunas novedades en cuanto al régimen jurídico de los contratos, en general, de los servicios ${ }^{52}$, en particular y también en temas de solvencia técnica, como se ha señalado. Si nos centramos en el contrato de servicios, una particularidad se produce en relación con la contratación de los servicios jurídicos, fundamentalmente por la distinta regulación de la Directiva 2014/24/ UE y la LCSP, puesto que nuestro legislador no ha transpuesto de igual forma dicha norma europea, distanciándose así de su regulación y de lo establecido en otros países de la Unión Europea que han sido más fieles a la regulación comunitaria. Y esta situación ha provocado, en poco tiempo, la reacción de nuestros órganos contractuales internos e, incluso, del propio TJUE.

La situación que se plantea es la siguiente: la Directiva 2014/24/UE contempla los servicios jurídicos como contratos de servicios específicos del anexo XIV, entendiendo que para estar sometidos a regulación armonizada su importe tiene que ser superior a $750.000 €$, salvo que se trate de servicios concretamente excluidos. Y excluye de su ámbito de aplicación determinados servicios jurídicos, en el art. 10.d) de la misma, concretamente aquellos que tengan como objeto:

i) «Representación legal de un cliente por un abogado, en el sentido del artículo 1 de la Directiva 77/249/CEE del Consejo (Considerando 25) en:

- un arbitraje o una conciliación celebrada en un Estado miembro, un tercer país o ante una instancia internacional de conciliación o arbitraje, o

- un procedimiento judicial ante los órganos jurisdiccionales o las autoridades públicas de un Estado miembro, un tercer país o ante órganos jurisdiccionales o instituciones internacionales.

ii) Asesoramiento jurídico prestado como preparación de uno de los procedimientos mencionados en el inciso i) de la presente letra, o cuando haya una indicación concreta y una alta probabilidad de que el asunto sobre el que se asesora será objeto de dichos procedimientos, siempre que el asesoramiento lo preste un abogado en el sentido del artículo 1 de la Directiva 77/249/CEE.

51 Respecto a dicha documentación, el TJUE admite que se presenten documentos que no figuraban en la oferta inicial cuando constituyan una mera aclaración puntual o una corrección de errores materiales manifiestos, porque de lo contrario se podría entender que se está produciendo una modificación sustancial de la oferta inicial (STJUE de 7 de abril de 2016, asunto C-324/14, Partner Apelski Dariusz).

${ }^{52}$ CASTIÑEIRA PIÑEIRO, J. C. (2018), "Los contratos de servicios en la Ley de Contratos del Sector Público", en Revista de Estudios Locales CUNAL, núm. 205, pág. 318 y ss.; RUBIO BELTRÁN, J. (2019), "La contratación de los servicios jurídicos en la le 9/2017, de 8 de noviembre, de Contratos del Sector Público", en REALA, Nueva Época, núm. 11, pág. 184 y ss. 
iii) Servicios de certificación y autenticación de documentos que deban ser prestados por un notario.

iv) Servicios jurídicos prestados por administradores, tutores u otros servicios jurídicos cuyos proveedores sean designados por un órgano jurisdiccional en el Estado miembro en cuestión o designados por ley para desempeñar funciones específicas bajo la supervisión de dichos órganos jurisdiccionales.

v) Otros servicios jurídicos que en el Estado miembro de que se trate estén relacionados, incluso de forma ocasional, con el ejercicio del poder público».

La justificación de esta exclusión se encuentra en el considerando 25 de la propia Directiva cuando afirma que «...Dichos servicios jurídicos son prestados normalmente por organismos o personas nombrados o seleccionados mediante un procedimiento que no puede regirse por las normas de adjudicación de los contratos, como ocurre, por ejemplo, en algunos Estados miembros, con el nombramiento del Ministerio fiscal. Por consiguiente, estos servicios jurídicos quedan excluidos del ámbito de aplicación de la presente Directiva». Aunque el ejemplo que utiliza la Directiva no sirve precisamente para justificar, por la misma razón, los servicios de defensa y dirección letrada en cualquier tipo de proceso judicial o extrajudicial así como el asesoramiento previo a cualquier Entidad del Sector Público ${ }^{53}$, puesto que no es la misma la forma de elección del Ministerio Fiscal que en los casos de servicios de defensa y dirección letrada.

En el Derecho interno, los servicios jurídicos no tienen una regulación específica diferente al resto de servicios. Partiendo de la definición general del contrato de servicios que da el art. 17 LCSP, en los artículos 11.2 y 3 solamente se excluye de la aplicación de la Ley, «... las relaciones jurídicas consistentes en la prestación de un servicio público cuya utilización por los usuarios requiera el abono de una tarifa, tasa o precio público de aplicación general», así como «los contratos relativos a servicios de arbitraje y conciliación». El resto de contratos de servicios jurídicos, incluidos los que la Directiva excluye, quedan sometidos a los preceptos de la LCSP, aunque con un régimen especial precisamente para aquellos que son excluidos por dicha Directiva. Se trata del art. 19.2.e), que excluye de la regulación armonizada aquellos contratos que tengan por objeto alguno de los siguientes servicios jurídicos:

«1. ${ }^{\circ}$ La representación y defensa legal de un cliente por un procurador o un abogado, ya sea en un arbitraje o una conciliación celebrada en un Estado o ante una instancia internacional de conciliación o arbitraje, o ya sea en un procedimiento judicial ante los órganos jurisdiccionales o las autoridades públicas de un Estado o ante órganos jurisdiccionales o instituciones internacionales.

2. ${ }^{\circ}$ El asesoramiento jurídico prestado como preparación de uno de los procedimientos mencionados en el apartado anterior de la presente letra, o cuando exista una probabilidad alta de que el asunto sobre el que se asesora será objeto de dichos procedimientos, siempre que el asesoramiento lo preste un abogado.

3. ${ }^{\circ}$ Los servicios de certificación y autenticación de documentos que deban ser prestados por un notario público.

$4 .^{\circ}$ Los servicios jurídicos prestados por administradores, tutores u otros servicios jurídicos cuyos prestadores sean designados por un órgano jurisdiccional o designados por Ley para desempeñar funciones específicas bajo la supervisión de dichos órganos jurisdiccionales.

$5 .^{\circ}$ Otros servicios jurídicos que estén relacionados, incluso de forma ocasional, con el ejercicio del poder público».

Sobre esta regulación, la Junta Consultiva de Contratación Pública del Estado ha elaborado su Informe 4/2019, sobre consulta planteada por el Presidente de la Diputación Provincial de Guadalajara, haciendo suyas las argumentaciones de la Abogacía General del Estado en su informe Ref: A. G.- ENTES PÚBLICOS 45/2018 (R-436/2018), con cita de otros informes precedentes (de 20 de febrero de 2018, referencia A. G. Varios 1/2018, R-176/2018), así como la aplicación de los principios generales a los que alude la Comunicación Interpretativa de la Comisión sobre el Derecho comunitario aplicable a la adjudicación de contratos no

53 SAZ CORDERO, S. (2019), "La contratación de los servicios jurídicos por las entidades del sector público", en El Consultor de los Ayuntamientos, núm. 1, pág. 88 y ss. entiende que un posible motivo de exclusión puede ser la presión de la profesión en el ámbito europeo. 
cubiertos o sólo parcialmente cubiertos por las directivas sobre contratación pública, publicada en el diario Oficial de la Unión Europa de 1 de agosto de 2006. Sería esta, a juicio de la Abogacía General del Estado y de la propia JCCAE, la normativa aplicable, que garantiza la aplicación de unos principios generales que flexibilizan considerablemente el procedimiento de adjudicación ${ }^{54}$, sin que ello impida la aplicación de cualesquiera de los procedimientos de adjudicación que regula la LCSP.

En este caso, entiende la Junta Consultiva en el Informe analizado, que la contratación deberá efectuarse de forma conjunta, mediante la adjudicación de un solo contrato, teniendo en cuenta la cuantía global de todos los juicios o prestaciones jurídicas que comprenda, o en su caso el plazo de duración del servicio de defensa legal, con respeto absoluto por los principios de publicidad y libre concurrencia, por lo que es aconsejable la celebración de un único contrato de representación y defensa en juicio y no de uno por cada juicio que se celebre. Aunque, dada la especificidad o excepcionalidad de determinados casos, que pueden requerir una especialización jurídica determinada, también se puede contratar de forma singular para un pleito determinado, previa justificación de esta peculiaridad en el expediente.

Sobre esta cuestión, que dará sin lugar a dudas pie para muchas más páginas de doctrina y decisiones de nuestros Tribunales, se ha pronunciado también recientemente la STJUE de 6 de junio de 2019 (asunto C-264/18), que resuelve una cuestión prejudicial en la que se plantean si el artículo 10, letras c) y d), incisos i), ii) y v) de la Directiva comentada es compatible con el principio de igualdad, en relación con el principio de subsidiariedad y con los artículos 49 y 56 TFUE, por relación a la exclusión de los servicios jurídicos de su ámbito objetivo de aplicación que realiza la normativa belga de transposición de la Directiva.

En esta sentencia el Tribunal entiende que la Directiva no infringe el principio de igualdad precisamente por la mutua confianza y la confidencialidad como rasgos que caracterizan a estos servicios jurídicos, lo que los distingue de otros servicios de carácter intelectual y justifica su exclusión del ámbito de aplicación de la Directiva ${ }^{55}$. Son la mutua confianza y la confidencialidad los rasgos que justifican tanto la no vulneración del principio de igualdad, como la exclusión de un procedimiento ordinario de contratación, línea a la que apunta en último lugar el Informe de la JCCA comentado, con una cierta contradicción con la STJUE ${ }^{56}$.

54 Reproducimos aquí algunos párrafos del Informe 4/2019: afirma la JCCAE, en su apartado 4 que «...cuando la Directiva decide excluir de su ámbito propio a un determinado servicio no cabe duda de que el legislador español actúa correctamente excluyendo estos servicios de la regulación armonizada, que representa el máximo nivel de sujeción al derecho público. Sin embargo, la anterior conclusión no quiere decir que estos contratos tengan que ser obligatoriamente excluidos del ámbito de aplicación de la legislación interna. Antes al contrario, el legislador interno goza de potestad de permitir su regulación por la norma contractual pública del Estado miembro en cuestión, a pesar de que por expresa indicación del derecho comunitario no estén sujetos a la Directiva».

Por lo tanto, en el caso que nos atañe, esto es, la prestación de servicios consistentes en la defensa legal de las Administraciones Públicas mediante abogado, tal prestación nunca puede ser calificada como contrato sujeto a regulación armonizada cualquiera que sea su valor estimado, pero eso no implica que no puedan calificarse como contratos de servicios a los efectos de la aplicación de las reglas sobre contratación pública que fueran procedentes en cada caso.

Esta decisión del legislador español es perfectamente congruente con el texto y el espíritu de la Directiva y no puede calificarse como una incorrecta transposición de la misma.

Y después de declarar la aplicación de esos principios generales de la Comunicación comunitaria a la que hemos hecho referencia, señala que es indiferente la naturaleza pública o privada de la entidad contratante y del carácter administrativo o privado del contrato resultante, continúa afirmando que «....corresponderá a la entidad adjudicadora del contrato decidir si el mismo encierra potencialmente interés para los operadores económicos de otros Estados de la Unión Europea. Si así fuese deberían tenerse en cuenta los criterios establecidos en la Comunicación que exigen la publicación del anuncio en el sitio web de la entidad adjudicadora, la descripción no discriminatoria del objeto del contrato, igualdad de acceso para los operadores económicos y plazos adecuados para la presentación de ofertas. Si, por el contrario, carece el contrato de interés para los operadores económicos de otros Estados miembros, sería admisible prescindir del requisito de publicidad y limitar el número de empresas a las que se solicite ofertas». Y esta conclusión no excluye que pueda ser utilizado cualquier de los procedimientos de adjudicación de la LCSP «pues la legislación comunitaria y la LCSP constituyen una normativa de mínimos que no impide la aplicación de un procedimiento más riguroso».

55 Entiende el Tribunal que los «...servicios prestados por un abogado solo se conciben en el marco de una relación intuitu personae entre el abogado y su cliente, marcada por la más estricta confidencialidad» y que dicha relación, caracterizada por la libre elección que el cliente hace de su abogado «dificulta la descripción objetiva de la calidad esperada de los servicios que hayan de prestarse». Entiende el Tribunal que dicha confidencialidad trata tanto de salvaguardar el pleno ejercicio de los derechos de defensa de los justiciables, como de proteger la exigencia de que todo justiciable tenga la posibilidad de dirigirse con entera libertad a su abogado y que la misma «podría verse amenazada por la obligación del poder adjudicador de precisar las condiciones de adjudicación de ese contrato y la publicidad que debe darse a tales condiciones».

56 En un comentario a esta sentencia TEJEDOR BIELSA, J. (2019), "La frustrada flexibilidad en España de los servicios jurídicos promovida por la normativa europea", en la página web (consultada el 08-07-2019), https://www.administracionpublica.com/la-frustrada-flexibilidad-en-espana-de-los-servicios-juridicos-promovida-por-la-normativa-europea/\#, entiende que la forma en que el legislador español de contratos ha llevado a nuestra LCSP la exclusión que hace la Directiva comunitaria «no resulta coherente con las razones que llevaron al legislador europeo a excluirlos para que tuviesen un régimen más flexible. El resultado es incoherente, algo demasiado habitual en nuestra normativa básica contractual». 
La mutua confianza, la confidencialidad, entre el cliente, público o privado, y el profesional, que caracterizan al contrato de servicios jurídicos, como hemos señalado, afectan también a la solvencia técnica, en especial al requisito de la experiencia que hemos analizado en páginas precedentes. Dicha experiencia se demuestra, bien por haber presado servicios en el ámbito local ${ }^{57}$, bien en un ámbito específico de la jurisdicción ${ }^{58}$, aunque ya hemos visto también que en ocasiones se han exigido un número excesivo de años, o de asuntos, lo que ha sido calificado por nuestros órganos contractuales como desproporcionado. En otras ocasiones no ha sido considerado así por el propio TACRC que ha considerado válido, desestimando el recurso especial correspondiente, que la solvencia relativa a los principales servicios o trabajos realizados de igual o similar naturaleza puede acreditarse aportando copias simples de sentencias que así lo acrediten, por tratarse de un medio opcional que no excluye otras formas de acreditación ${ }^{59}$. Entiende el Tribunal que en este supuesto el criterio establecido en los pliegos ni es desproporcionado ni supone una restricción injustificada de la competencia o del principio de igualdad entre los posibles licitadores. En otra resolución, el Tribunal, partiendo del análisis de la regulación comunitaria sobre los contratos de servicios jurídicos, como hemos tenido ocasión de establecer en párrafos anteriores, analiza también criterios de solvencia técnica exigidos en los pliegos de la licitación, pero para llegar en este caso a la conclusión de que los licitadores no cumplían el mínimo de experiencia exigido por dichos pliegos ${ }^{60}$, sin que se hubiera planteado ninguna duda sobre la legalidad del clausulado de los mismos.

Nada impediría, evidentemente, el demostrar la experiencia a través de los títulos académicos y profesionales del personal relacionado en este caso con el abogado que presta los servicios jurídicos, así como integrar dicha experiencia a través de medios profesionales externos, pero, entiendo, sin que sea admisible la subcontratación, dada esa especial relación de confianza a la que se ha hecho alusión.

\section{CONCLUSIONES FINALES}

La nueva LCSP ha supuesto importantes modificaciones en materia de contratación pública, entre otros aspectos, en el tema de la solvencia técnica y la valoración de la experiencia de los licitadores, que

57 Por ejemplo, en poblaciones de población superior a 20.000 habitantes, aunque como ya hemos visto, los Tribunales de contratación entienden que estas exigencias limitan la concurrencia y son desproporcionadas, y que pueden utilizarse fórmulas alternativas para el ámbito local. Resolución 333/2016, de 29 de abril, del TACPM, mencionada anteriormente.

58 Por ejemplo, la contencioso-administrativa, o haber estado colegiado como abogado ejerciente durante un tiempo superior a 10 años, siendo así que los funcionarios públicos también han podido adquirir en su vida laboral amplios conocimientos jurídico administrativos. Entre otras, Resoluciones del TACRC 207/2014, de 14 de marzo y 238/2016, de 1 de abril. Y Resolución del TARC de Castilla y León 79/2016, de 16-11-2016, mencionada también con anterioridad.

59 El supuesto se planteaba en la Resolución del TACRC 1021/2018, de 12 de noviembre, en un recurso especial frente a los pliegos de contratación de unos servicios de asistencia jurídica y defensa judicial del Ayuntamiento de Denia. La resolución analiza si resulta válido un criterio que consiste en atribuir 10 puntos, 0,5 por cada sentencia favorable, recogido en los pliegos, y concluye que, aunque sea imperfecto, es válido y adecuado. El recurrente había señalado que la atribución de esa puntuación por sentencias favorables es contraria a la Ley porque la obtención de una sentencia favorable no depende exclusivamente de la labor profesional del abogado, sino que depende de una infinidad de factores ajenos a la calidad del trabajo de este. Afirma el Tribunal lo siguiente: «...En este caso vemos que la exigencia de la solvencia profesional que se cuestiona aparece en el anuncio de licitación y en el pliego y, siendo un contrato de servicios de asistencia jurídica, se puede considerar perfectamente válido y vinculado a su objeto, que se presenten las sentencias judiciales en el número exigido por el pliego, favorables... pero es también cierto que, dentro de su imperfección, constituye un indicio objetivo y muy valioso para evaluar la calidad profesional de la actuación de los abogados en el ámbito procesal que se trata de valorar. En este caso, a la aportación de sentencias favorables se le da una puntuación de 10 sobre 60 , en concreto de 0,5 puntos a cada sentencia favorable, hasta llegar al máximo de los 10 puntos, lo que implica que, en definitiva, se van a valorar hasta un tope de 20 sentencias favorables, y correspondientes todas ellas a dos años (2016 y 2017). A juicio de este Tribunal no parece desproporcionada la exigencia de que se aporten un mínimo de 20 sentencias favorables obtenidas en dos años, teniendo en cuenta, además, que no se trata de un umbral técnico, es decir, no es un tope mínimo sin el cual no se pueda admitir al licitador que no las presente, sino que opera tan solo como un criterio de valoración, de manera que no limita ni restringe el derecho o la condición del licitador, sino que solo atribuye mayor puntuación al licitador que acredite haber obtenido mayor número de sentencias favorables...Por lo tanto, es opinión de este Tribunal que este criterio de valoración resulta plenamente válido, sin suponer una restricción injustificada de la competencia o del principio de igualdad en la presente licitación, ya que no limita los derechos de los licitadores, ni supone una carga desproporcionada para los mismos, por todo ello, este criterio, a juicio de este Tribunal, cumple con lo dispuesto dentro de la LCSP».

60 Se trata en este caso de la Resolución del TACRC 715/2018, de 27 de julio, sobre servicio de asesoría y representación jurídica en el ámbito de la seguridad social, civil y penal vinculado a los accidentes de trabajo in itinere o en misión para MAZ, Mutua de accidentes de trabajo y enfermedades profesionales de la Seguridad Social y los criterios de solvencia técnica exigidos eran los siguientes: demostrar con un certificado de buena ejecución haber prestado este tipo de servicios en el ámbito de la Seguridad Social; y aportar currículo vitae que acreditara un mínimo de cinco años de colegiación y un mínimo de cinco años de ejercicio profesional en el ámbito de la Seguridad Social, concretamente en la defensa de las Mutuas Colaboradoras con la Seguridad Social. 
ha sido precisamente el objeto de estudio de este trabajo. Se han analizado numerosas resoluciones de órganos contractuales, tanto de las Juntas Consultivas de Contratación, bien de la estatal o de las distintas Comunidades Autónomas, como de los Tribunales de Recursos Contractuales, así como jurisprudencia de nuestros Tribunales y del TJUE, observándose, en general, una interpretación más favorable a la contratación que la que había sido exigida previamente por los pliegos de contratación analizados, que vulneraban en ocasiones los principios de proporcionalidad, igualdad, no discriminación, concurrencia e integridad.

Esta interpretación más favorable se producía ya con anterioridad, incluso, a la entrada en vigor del nuevo paquete normativo comunitario de 2014 y que dio lugar a la última modificación de la legislación en materia contractual. Como consecuencia de la misma, y dentro de una acción positiva de las políticas públicas, se introdujeron en la nueva LCSP medidas tendentes a proteger a las PYMES, en la fase de licitación que aquí se analiza, en cuanto a requisitos de solvencia técnica y experiencia exigidas a las mismas, reduciendo el número de años a tener en cuenta para acreditar dicha experiencia. Medida que se implementa también para las empresas de nueva creación, que no pueden, precisamente por dicha circunstancia, demostrar experiencia previa. Se ha analizado, además, favoreciendo a mayores esta situación, la acreditación acudiendo a medios externos, así como los valores transversales relativos al valor social y ambiental y el papel que pueden jugar en dicha acreditación.

Por último, una precisión respecto a la regulación de la prestación de servicios jurídicos, con la paradoja inicial que se encuentra cualquier estudioso de esta materia, de que la regulación nacional es distinta a la comunitaria. No es que esta evidencia resulte novedosa respecto a la forma de actuar de nuestro legislador en otras ocasiones, pero pensemos que si la pretensión comunitaria es favorecer una mayor competencia al excluir determinados contratos de servicios jurídicos del ámbito de la aplicación de la Directiva, ello no se consigue, si nuestro legislador los sigue sometiendo al ámbito de aplicación de la LCSP, bien que lo haga excluyéndolos del ámbito de aplicación de la regulación armonizada, con las implicaciones que ello conlleva. En relación con este tema, tampoco será una medida favorecedora de las PYMES la exigencia que nuestra Junta Consultiva de Contratación Pública del Sector Público hace de que la contratación se efectúe de forma conjunta a través de un único contrato en contradicción con la división por lotes por la que apuesta la nueva LCSP, aunque dicha división tampoco garantiza en realidad que las PYMES puedan acceder más y mejor al procedimiento de contratación.

\section{BIBLIOGRAFÍA}

ALMODÓVAR IÑESTA, M. (2019): "Las cláusulas sociales en la contratación pública”, en FERNÁNDEZ SALMERÓN, M. y MARTÍNEZ GUTIÉRREZ, R. (dirs.): Transparencia, innovación y buen gobierno en la contratación pública, pág. 387 y ss. Valencia: Tirant lo Blanch.

ALONSO GARCÍA, M. a C. (2015): "Las novedades introducidas por la Directiva 2014/24/UE en la contratación pública verde", en GIMENO FELIÚ, J. M.a , GALLEGO CÓRCOLES, I., HERNÁNDEZ GONZÁLEZ, F. y MORENO MOLINA, J. A.: Observatorio de los Contratos Públicos. Las nuevas Directivas de Contratación Pública: (Ponencias Sectoriales X Congreso Asociación Española Profesores de Derecho Administrativo), núm. monográfico especial, pág. 279 y ss. Navarra: Thomson Reuters Aranzadi.

BUDRÍA ESCUDERO, A. (2013): "La acreditación de la solvencia por medios externos", en Revista de Estudios Locales CUNAL, núm. 161 (extraordinario), pág. 235 y ss.

CARLÓN RUIZ, M. (2010): "El principio de proporcionalidad", en SANTAMARÍA PASTOR, J. A. (dir.): Los principios jurídicos del Derecho Administrativo, pág. 209 y ss. Madrid: La Ley.

CASTIÑEIRA PIÑEIRO, J. C. (2018): "Los contratos de servicios en la Ley de Contratos del Sector Público", en Revista de Estudios Locales CUNAL, núm. 205, pág. 318 y ss.

CEA AYALA, A. (2016): "Requisitos de solvencia del empresario", en Contratación Administrativa Práctica: Revista de la Contratación Administrativa y de los Contratistas, núm. 146, pág. 20 y ss.

CERRILLO I MARTÍNEZ, A. (2018): El principio de integridad en la contratación pública: mecanismos para la prevención de los conflictos de intereses y la lucha contra la corrupción. Navarra: Thomson Reuters Aranzadi.

CHINCHILLA MARÍN, C. (2011): "La jurisprudencia del TJUE sobre contratos públicos (I). Ámbito subjetivo y objetivo de aplicación de las Directivas”, en SÁNCHEZ MORÓN, M. (dir.); y DEL OLMO ALONSO, J. (coord.): El Derecho de los contratos públicos en la Unión Europea y sus Estados miembros, pág. 33 y ss. Valladolid: Lex Nova.

CUNILLERA BUSQUETS, M. (2013): "A vueltas con los requisitos de solvencia en las licitaciones administrativas. La Sentencia del Tribunal de Justicia de la Unión Europea, de 18 de octubre de 2012", en El Consultor de los Ayuntamientos, núm. 2, pág. 159 y ss. 
GALLEGO CÓRCOLES, I. (2014): "Aplicación de medidas de gestión medioambiental como requisito de acreditación de solvencia técnica", en Contratación Administrativa Práctica: Revista de la Contratación Administrativa y de los Contratistas, núm. 134, pág. 53 y ss.

GARCÍA SANTOS, J. y JURADO JIMÉNEZ, J. C. (2018): "Aptitud para contratar con el sector público. Capacidad y solvencia del empresario", en GAMERO CASADO, E. y GALLEGO CÓRCOLES, I. (dir.): Tratado de Contratos del Sector Público, vol. II, pág. 1.043 y ss. Valencia: Tirant lo Blanch.

GIMENO FELIÚ, J. M. ${ }^{a}$ (2012): "La necesidad de un Código de Contratos Públicos en España. La contratación pública y las PYMES como estrategia de reactivación económica”, en GIMENO FELIÚ, J. M. ${ }^{a}$ (dir.): Observatorio de los Contratos Públicos 2011, pág. 25 y ss. Navarra: Thomson Reuters Aranzadi.

GIMENO FELIÚ, J. M. ${ }^{a}$ (2013): "Novedades en la nueva normativa comunitaria sobre contratación pública”, en Revista de Estudios Locales CUNAL, núm. 161, pág. 15 y ss.

GIMENO FELIÚ, J. M. ${ }^{a}$ (2013): "Las nuevas Directivas -cuarta generación- en materia de contratación pública. Hacia una estrategia eficiente en compra pública”, en Revista Española de Derecho Administrativo, núm. 159, pág. 39 y ss.

GIMENO FELIÚ, J. M. ${ }^{a}$ (2014): El nuevo paquete legislativo comunitario sobre contratación pública. De la burocracia a la estrategia: El contrato público como herramienta de liderazgo institucional de los poderes públicos. Navarra: Thomson Reuters Aranzadi.

GIMENO FELIÚ, J. M. ${ }^{a}$ (2017): "La transposición de las directivas de contratación pública en España: una primera valoración de sus principales novedades", en Documentación Administrativa, DA. Nueva Época, núm. 4, pág. 7 y ss. DOI: $h$ ttps://doi.org/10.24965/da.v0i4.10493.

GIMENO FELIU, J. M. a (2017): "Medidas de prevención de corrupción y refuerzo de la transparencia en la contratación pública", en Revista de Estudios de la Administración Local y Autonómica, REALA. Nueva Época, núm. 7, pág. 45 y ss. DOI: https://doi.org/10.24965/reala.v0i7.10419.

GONZÁLEZ SANFIEL, A. M. (2015): "Integridad en la contratación pública: patologías al uso. A propósito del informe de la Comisión Europea sobre lucha contra la corrupción”, en GIMENO FELIÚ, J. M. ${ }^{a}$, GALLEGO CÓRCOLES, I., HERNÁNDEZ GONZÁLEZ, F. y MORENO MOLINA, J. A.: Observatorio de los Contratos Públicos. Las nuevas Directivas de Contratación Pública: (Ponencias Sectoriales X Congreso Asociación Española Profesores de Derecho Administrativo), núm. monográfico especial, pág. 253 y ss. Navarra: Thomson Reuters Aranzadi.

HERNANDO ACEVEDO, R. (2017): "Los retos ambientales de las nuevas directivas: la contratación pública como herramienta", en RAZQUIN LIZARRAGA, M. M. a (dir.): Nueva contratación pública: Mercado y Medio Ambiente, pág. 77 y ss. Navarra: Thomson Reuters Aranzadi.

HUERGO LORA, A. (2005): "El Derecho español de contratos públicos y el Derecho comunitario", en Revista Española de Derecho Administrativo, núm. 126, pág. 217 y ss.

HUERGO LORA, A. (2017): "La experiencia como requisito para contratar con el sector público y sus límites. Casos recientes", en Estudio Jurídico lus Publicum: Expertos en Derecho Administrativo (consultado 18-05-2019). URL: http://estudiojuridicoip.com/la-experiencia-requisito-solvencia-tecnica-profesional-contratar-sector-publico-limitescasos-recientes/.

LÓPEZ TOLEDO, P. (2014): "La contratación pública verde y su nueva regulación en el Derecho de la Unión Europea”, en Contratación Administrativa Práctica: Revista de la Contratación Administrativa y de los Contratistas, núm. 134, pág. 15 y ss.

MARTÍNEZ HELLÍN, J. (2011): "La adecuada determinación de los criterios de solvencia del contratista. Especial referencia al respeto a los principios de no discriminación e igualdad de trato”, en El Consultor de los Ayuntamientos, núm. 15-16, pág. 1.872 y ss.

MEDINA ARNÁIZ, T. (2015): "La aplicación de las prohibiciones de contratar según la jurisprudencia del Tribunal de Justicia de la Unión Europea”, en GIMENO FELIÚ, J. M. a , GALLEGO CÓRCOLES, I., HERNÁNDEZ GONZÁLEZ, F. y MORENO MOLINA, J. A.: Observatorio de los Contratos Públicos. Las nuevas Directivas de Contratación Pública: (Ponencias Sectoriales X Congreso Asociación Española Profesores de Derecho Administrativo), núm. monográfico especial, pág. 383 y ss. Navarra: Thomson Reuters Aranzadi.

MEDINA ARNÁIZ, T. (2016): "El Documento Europeo Único de Contratación. Un paso más para reducir la carga burocrática en la contratación pública", en GIMENO FELIÚ, J. M. ${ }^{a}$ (dir.): Observatorio de los Contratos Públicos 2015, pág. 247 y ss. Navarra: Thomson Reuters Aranzadi.

MEDINA ARNÁIZ, T. (2017): "El requisito de solvencia en la Ley de Contratos del Sector Público", en GIMENO FELIÚ, J. M. ${ }^{a}$ (dir.): Observatorio de los Contratos Públicos 2016, pág. 167 y ss. Navarra: Thomson Reuters Aranzadi.

MEDINA ARNÁIZ, T. (2018): Las prohibiciones de contratar desde una perspectiva europea. Navarra: Thomson Reuters Aranzadi.

MEDINA ARNÁIZ, T. (2019): "Avanzando en la reducción de las cargas administrativas vinculadas a la selección del contratista”, en FERNÁNDEZ SALMERÓN, M. y MARTÍNEZ GUTIÉRREZ, R. (dirs.): Transparencia, innovación y buen gobierno en la contratación pública, pág. 101 y ss. Valencia: Tirant lo Blanch.

MORENO MOLINA, J. A. (2000): "La reciente jurisprudencia del Tribunal de Justicia de las Comunidades Europeas en materia de contratos públicos", en Revista de Administración Pública, núm. 151, pág. 319 y ss.

MORENO MOLINA, J. A. (2006): Los principios generales de la contratación de las Administraciones Públicas. Albacete: Bomarzo. 
MORENO MOLINA, J. A. (2012): "El sometimiento de todos los contratos públicos a los principios generales de contratación", en GARCÍA DE ENTERRÍA, E. y ALONSO GARCÍA, R. (coords.): Administración y justicia: un análisis jurisprudencial. Liber amicorum Tomás-Ramón Fernández, pág. 3.492 y ss. Madrid: Thomson Reuters.

MORENO MOLINA, J. A. (2013): "La cuarta generación de Directivas de la Unión Europea sobre contratos públicos", en GIMENO FELIÚ, J. M. ${ }^{a}$ (dir.): Observatorio de los Contratos Públicos 2012, pág. 115 y ss. Navarra: Thomson Reuters Aranzadi.

MORENO MOLINA, J. A. (2014): "La nueva Directiva sobre contratación pública y su incorporación al Derecho español", en Contratación Administrativa Práctica: Revista de la Contratación Administrativa y de los Contratistas, núm. 129, pág. 16 y ss.

MORENO MOLINA, J. A. (2018): "Globalización en el derecho de la contratación pública”, en VAQUER CABALLERÍA, M., MORENO MOLINA, A. M. y DESCALZO GONZÁLEZ, A. (coords.): Estudios de Derecho Público en homenaje a Luciano Parejo Alfonso, vol. II, pág. 1.743 y ss. Valencia: Tirant lo Blanch.

MORENO MOLINA, J. A. y DOMÍNGUEZ ALONSO, A. P. (2014): "El nuevo derecho de la Unión Europea sobre contratación pública”, en VALCÁRCEL FERNÁNDEZ, P. y FERNÁNDEZ ACEVEDO, R. (dirs.): La contratación pública a debate: presente y futuro, pág. 139 y ss. Navarra: Thomson Reuters Aranzadi.

PERNAS GARCÍA, J. J. (2012): "El uso estratégico de la contratación pública como apoyo a las políticas ambientales", en LÓPEZ RAMÓN, F. (coord.): Observatorio de Políticas Ambientales 2012, pág. 299 y ss. Navarra: Thomson Reuters Aranzadi.

PERNAS GARCÍA, J. J. (2014): "La dimensión ambiental en la normativa de contratos del sector público", en VALCÁRCEL FERNÁNDEZ, P. y FERNÁNDEZ ACEVEDO, R. (dirs.): La contratación pública a debate: presente y futuro, pág. 345 y ss. Navarra: Thomson Reuters Aranzadi.

RAZQUIN LIZARRAGA, M. M. a (2000): "La jurisprudencia del Tribunal de Justicia de las Comunidades Europeas sobre contratación pública", en Justicia Administrativa: Revista de Derecho Administrativo, núm. 6, pág. 5 y ss.

RAZQUIN LIZARRAGA, M. M. a (2015): "Las nuevas Directivas sobre contratación pública de 2014: aspectos clave y propuestas para su transformación en España”, en Revista de Administración Pública, núm. 196, pág. 97 y ss.

RAZQUIN LIZARRAGA, M. M. a (2017): "Mecanismos para la inclusión de cláusulas ambientales en los contratos públicos", en RAZQUIN LIZARRAGA, M. M. ${ }^{a}$ y ALENZA GARCÍA, J. F. (coords.): Nueva contratación pública, mercado y medio ambiente. Congreso Internacional Nueva Contratación Pública: mercado y medio ambiente 2016, pág. 147 y ss. Navarra: Thomson Reuters Aranzadi.

RAZQUIN LIZARRAGA, M. M. ${ }^{a}$ (2018): "Los principios generales de la contratación pública”, en GAMERO CASADO, E. y GALLEGO CÓRCOLES, I. (dirs.): Tratado de Contratos del Sector Público, vol. I, pág. 181 y ss. Valencia: Tirant lo Blanch.

RUBIO BELTRÁN, J. (2019): "La contratación de los servicios jurídicos en la le 9/2017, de 8 de noviembre, de Contratos del Sector Público", en Revista de Estudios de la Administración Local y Autonómica, REALA. Nueva Época, núm. 11, pág. 184 y ss. DOI: https://doi.org/10.24965/reala.v0i11.10570.

SANTAMARÍA PASTOR, J. A. (2016): "Contratos del sector público y derecho de la Unión", en Revista de Administración Pública, núm. 200, pág. 83 y ss. DOI: https://doi.org/10.18042/cepc/rap.200.05.

SANTAMARÍA PASTOR, J. A. (2013): "La constante e interminable reforma de la normativa sobre contratación pública", en Revista Española de Derecho Administrativo, núm. 159, pág. 25 y ss.

SARASÍBAR IRIARTE, M. (2015): "La contratación pública se tiñe de verde", en GIMENO FELIÚ, J. M. a, GALLEGO CÓRCOLES, I., HERNÁNDEZ GONZÁLEZ, F. y MORENO MOLINA, J. A.: Observatorio de los Contratos Públicos. Las nuevas Directivas de Contratación Pública: (Ponencias Sectoriales X Congreso Asociación Española Profesores de Derecho Administrativo), núm. monográfico especial, pág. 317 y ss. Navarra: Thomson Reuters Aranzadi.

SAZ CORDERO, S. (2019): "La contratación de los servicios jurídicos por las entidades del sector público", en El Consultor de los Ayuntamientos, núm. 1, pág. 88 y ss.

TEJEDOR BIELSA, J. (2018): La contratación pública en España ¿sobrerregulación o estrategia?: Causas y consecuencias de su problemática aplicación. Madrid: Thomson Reuters.

TEJEDOR BIELSA, J. (2019): "La frustrada flexibilidad en España de los servicios jurídicos promovida por la normativa europea”, en El blog de esPublico. Mejor blog nacional público (consultado 08-07-2019). URL: https:// www.administracionpublica.com/la-frustrada-flexibilidad-en-espana-de-los-servicios-juridicos-promovida-por-lanormativa-europea/\#.

VÁZQUEZ MATILLA, F. J. (2018): "La solvencia en la nueva LCSP”, en GIMENO FELIU, J. M. (dir.): Estudio sistemático de la Ley de Contratos del Sector Público, pág. 715 y ss. Navarra: Thomson Reuters. 